\title{
Characterization of Chemical Waste Site Contamination and Its Extent Using Bioassays
}

J. M. Thomas

C. A. Callahan

J. F. Cline

J. C. Greene

M. C. McShane
W. E. Miller

S. A. Peterson

J. C. Simpson

J. R. Skalski

December 1984

Prepared for the

U.S. Environmental Protection Agency under a Related Services Agreement with the U.S. Department of Energy

Contract DE-AC06-76RLO 1830

Pacific Northwest Laboratory Operated for the U.S. Department of Energy by Battelle Memorial Institute 
Although the research described in this article has been funcled wholly or in part by the United States Environmental Protection Agency (EPA), it has not been subjected to EPA review and therefore does not necessarily reflect the views of EPA and no official endorsement should be inferred.

\title{
DISCLAIMER
}

This report was prepared as an account of work sponsored by an agency of the United States Government. Neither the United States Government nor any agency thereof, nor any of their employees, makes any warranty, express or implied, or assumes any legal liability or responsibility for the accuracy, completeness, or usefulness of any information, apparatus, product, or process disclosed, or represents that its use would not infringe privately owned rights. Reference herein to any specific commercial product, process, or service by trade name, trademark, manufacturer, or otherwise, does not necessarily constitute or imply its endorsement, recommendation, or favoring by the United States Government or any agency thereof. The views and opinions of authors expressed herein do not necessarily state or reflect those of the United States Government or any agency thereof.

\author{
PACIFIC NORTHWEST LABORATORY \\ operated by \\ BATTELLE \\ for the \\ UNITED STATES DEPARTMENT OF ENERGY \\ under Contract DE-AC06-76RLO 1830
}

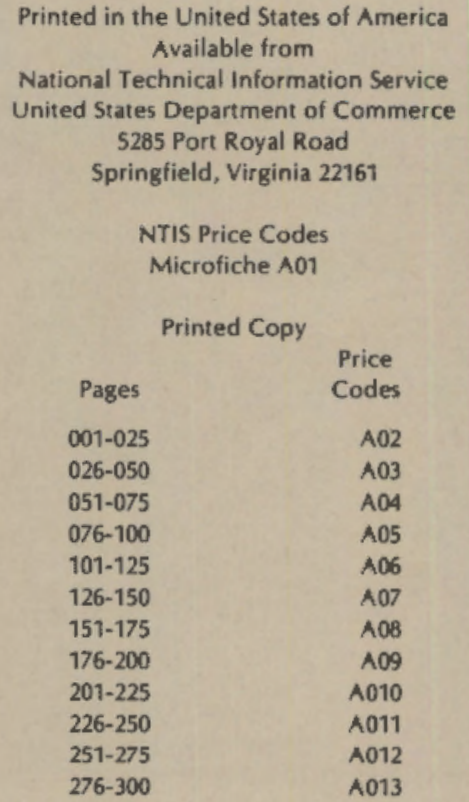


J. M. Thomas

(a)

W. E. Milier(a)

C. A. Callahan (a)

S. A. Peterson

J. F. Cline

3. C. Simpson

J. C. Greene (a)

J. R. Ska!ski

M. C. McShane

December 1984

Prepared for the

U.S. Environmental Protection Agency under a Related Services Agreement with the U.S. Department of Energy Contract DE-AC06-76RL0 1830

Pacific Northwest Laboratory

Richland, Washington 99352
(a) U.S. Environmental Protection Agency' Corvallis Environmental Resea "ch Laboratory Corvaltis, Oregon 97330




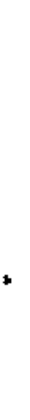




\section{PREFACE}

This inited distribution report documents the cooperative work of CERL and PNL on the use of bioassays to detect contamination at hazardous chemicai waste sites. With minor changes (Figures 5, 8 and 9 and associated discussion and the section on costs, page 2, will be deleted), the manuscript will eventually be submitted for pubtication in a refereed journal. 


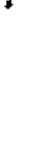

, 
Bioassays were used in a three-phase research project to assess the comparative sensitivity of test organisms to known chemicals, determine if the chemical components in field soil and water samples containing unknown contaminants could be inferred from our laboratory studies using known chemicals, and to investigate kriging (a relatively new statistical "mapping" technique) and bioassays as methods to define the areal extent of chemical contamination. The algal assay generally was most sensitive to samples of pure chemicals, soil elutriates and water from eight sites with known chemical contamination. Bioassays of nine samples of unknown chemical composition from the Rocky Mountain Arsenal (RMA) site showed that a lettuce seed soil contact phytoassay was most sensitive. In general, our bioassays can be used to broadly identify toxic components of contaminated soil. Nearly pure cornpounds of insecticides and herbicides were less toxic in the sensitive bioassays than were the counterpart commercial formulations. This finding indicates that chemical analysis alone may fail to correctly rate the severity of environmental toxicity. Finally, we used the lettuce seed phytoassay and kriging techniques in a field study at RMA to demonstrate the feasibility of mapping contamination to aid in cleanup decisions. 


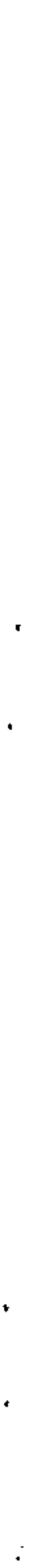




\section{ACKNOWLEDGEMENTS}

The technical help of Dr. Dave Thorne, Dr. Bill Trautman, and Mr. Brian Anderson and the cooperation of Dr. William McNeill of the Rocky Mountain Arsenal were essential in accomplishing this research. At the Pacific Northwest Laboratory, Mary Jo Harris supplied technical support. 


\section{CONTENTS}

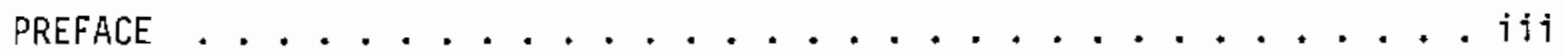

SUMMARY . . . . . . . . . . . . . . . . . . . . . . V

ACKNOWLEDGEMENTS . . . . . . . . . . . . . . . . . . . . . vii

INTRODUCTION . . . . . . . . . . . . . . . . . . . . . . . 1

SENSITIVITY OF BIOASSAYS TO CHEMICAL SUBGROUPS . . . . . . . . . 3

METHODS ......................... 3

Heavy Metals.................. . . . 4

Herbicides ................... 6

Insecticides................... 8

DISCUSSION . . . . . . . . . . . . . . . . . . . 9

TOXICITY OF CHEMICAL WASTE SITE SAMPLES . . . . . . . . . . . 11

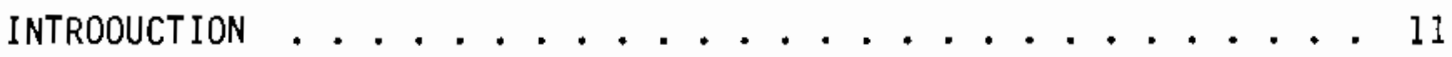

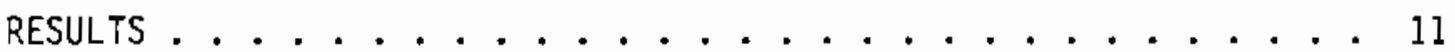

Rocky Mountain Arsenal . . . . . . . . . . . . . . 11

Other Waste Sites . . . . . . . . . . . . . 15

DISCUSSION ....................... 16

FIELD STUDY . . . . . . . . . . . . . . . . . . . . . 19

STUDY SITE . . . . . . . . . . . . . . . . 19

SOIL SAMPLING ....................... 19

PHYTOASSAY OF SOIL . . . . . . . . . . . . . . 20

RESULTS FROM OTHER BIOASSAYS . . . . . . . . . . . . 22

CLEANUP DECISION BASED ON BIOASSAYS AND KRIGING . . . . . . . 25

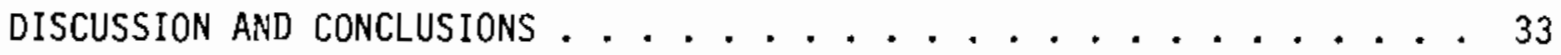

REFERENCES ........................ 35 


\section{TABLES}

1 Mean EC50 (mg/L), Coefficient of Variation, and Number of Bioassays for Several Species Using Copper, Cadmium and Zinc ... 5

2 Mean Bioassay EC50 ( $\mathrm{mg} / \mathrm{L}$ ) Coefficient of Variation and Number of Bioassays for Two Herbicides . . . . . . . . . . . . 6

3 Mean EC50 Values (mg/L) for Water Soluble Concentrations of Aldrin, Dieldrin, Endrin, Chlordane and Heptachlor from Chem Services, Westchester, Pennsylvania, and the EPA Repository of Toxic and Hazardous Materials ............. 7

4 Summary of EC50 (mg/L) Results in Tables 1-3, for Heavy Metals, Herbicides and Insecticides for Six Bioassays ........ 7

5 Concentrations of Aldrin, Dieldrin, Endrin, Chlordane and Heptachlor (mg/L) in Water Soluble Assay Samples ........ 9

6 EC50 Response or Percent Inhibition Caused by Chemica T Contaminants in Rocky Mountain Arsenal Soil, Soil Elutriate, Waste Water and Groundwater Samples ............. 12

7 EC50 Response (\% Soil for the Earthworm Test) to Chemical Contaminants in Hazardous Waste Site Soil and Soil Elutriate Samples ........................ 15

8 Comparison of Mean Percent Lettuce Seed Mortality in $0-15 \mathrm{~cm}$ (Experiment 1) and 15-30 $\mathrm{cm}$ (Experiment 2) Fractions of

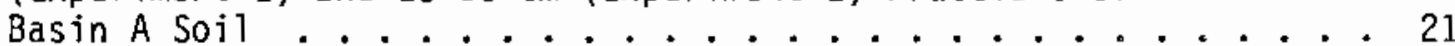

9 Intercomparison of Lettuce Root Elongation (RE), Lettuce Seed Mortality (MN), Earthworm Mortality (EW) and Algal Inhibition (S) for Two Fractions of Basin A Soils Obtained from the Rocky Mountain Arsena $\ldots \ldots . \ldots 23$ 


\section{FIGURES}

1 Location of the Study Site in Basin A (Section 36) at the

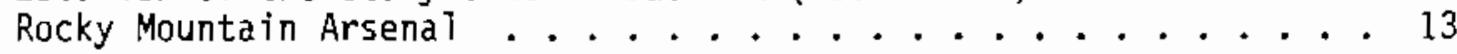

2 Location of Soil Sampling Points in Basin A (Section 36) at the Rocky Mountajn Arsenal ................ 14

3 A Comparison of Earthworm and Lettuce Seed Mortality Using Basin A Soils from Rocky Mountain Arsenal . . . . . . . . . . 24

4 A Comparison of Lettuce Root Elongation and Lettuce Seed Mortality Using Basin A Soils from Rocky MOuntain Arsenal . . . . . . . . 25

5 A Comparison of Lettuce Root Elongation and Earthworm Mortality Using Basin A Soils from Rocky Mountain Arsenal . . . . . . . . 26

6 Estimated Lettuce Seed Mortality (Based On Kriging) for the 0-15 cm Soil Fraction from the Rocky Mountain Arsenal . . . . . . . . . 27

7 Estimated Lettuce Seed Morta?ity (Based on Kriging) for the 15-30 cm Soil Fraction from the Rocky Mountain Arsenal . . . . . . . 28

8 A Comparison of Greater Than 30\% Lettuce Seed Mortality (Estimated from Kriging) to Observed Lettuce Seed Mortaltiy for the 0-15 cm Soil Fraction from the Rocky Mountain Arsenal . . . . . 29

9 A Comparison of Greater Than 30\% Lettuce Seed Mortality (Estimated from Kriging) to Observed Lettuce Seed Mortaltiy for the 15-30 cm Soil Fraction from the Rocky Mountain Arsenal . . . . 30 


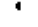

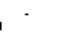

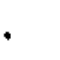




\section{INTRODUCTION}

The purpose of using bioassays to evaluate soils, soil elutriates, and surface and subsurface water from hazardous chemical waste sites is to provide an integrated estimate of environmental toxicity. Based on bioassay data, chemical waste sites can be ranked according to their toxic potential or mapped for cleanup operations. Since chemical waste sites are seldom contaminated with single compounds, chemical analysis can be expensive and, in fact, uninformative regarding environmental hazard. Samoiloff et al. (1983) have successfully used two bioassays, Salmonella typhimurium (Ames) and Panagrellus redivivus (a nematode), in concert with chemical fractionation, to identify toxic compounds in cores of lake sediments. They found that the "most toxic fractions contained none of the priority toxic chemicals." Hoffmann (1982), also offers mutagenicity testing of environmental samples as a cost effective way to screen samples. Our view supported by data from this study as well as by Mount et a1. (1984), is that several different bioassays may be needed to assess environmental risk.

The matter of analytic costs is not trivial. Schaeffer et a!. (1982) report that costs for complete chemical analyses of one sample can range from $\$ 2000$ - $\$ 5000$. As of June 1,1984 , one commercial laboratory (Aquatic Toxicology Division of Analytical Bio-Chemistry Laboratories, P.0. Box 1097, Columbia, Missouri 65205) advertised prices of $\$ 950$ for a static 96-hour algal assay and $\$ 650$ for a 48 -hour Daphnia magna test. Our preliminary calculations indicate that three replicate determinations of lettuce seed mortality (100\% soil) would cost about $\$ 130-\$ 150$. Thus the total cost per sample depends on the chemical andlyses needed or the number of bioassays selected. Schaeffer et al. (1982) suggest compositing to reduce the overall cost. This proposal merits serious consideration (Skaiski and Thomas, 1984). Other cost-reducing alternatives include the assays suggested by Samoiloff (1983) or Hoffman (1982). Based on the studies discussed in this paper, microbial assays (e.g., dissolved oxygen and Microtox) may not be sufficiently sensitive. 
The objectives of this study were to assess the comparative sensitivity of test organisms to known chemicals, determine whether the chemical components in fieid soil and water sampies containing unknown contaminants could be inferred from our laboratory studies using known chemicals, and to investigate kriging (a relatively new statistical "mapping technique") of bioassay results as a method to define the areal extent of contamination. In support of these objectives, we first present data on the response of the organisms listed in the Hazardous Materials Assessment Team (HMAT) test protocol (Porcella, 1983) to pure chemicals from three chemical subgroups (heavy metals, insecticides and herbicides); their response to waste site soils, soil elutriates and water in an attempt to identify chemical components in samples where the major contaminants are known, and to Rocky Mountain Arsena 1 (RMA) waste site soils and waste water basins where the chemical constituents must be inferred from past plant operations. Next, we present the results of a field study at RMA, designed to investigate whether bioassay results can be used to prepare a map of suspected contamination. 


\section{SENSITIVITY OF BIOASSAYS TO CHEMICAL SLUGGROLPS}

METHODS

All chemicals, waste site soils and surface water and groundwater samples were assayed using algae, Daphnia, earthworm and root elongation tests in accord with the procedures described in the HMAT protocol for Bioassessment of Hazardous Waste Sites (Porcelia, 1983). The Microtox tests were conducted as outlined in the instrument operation manual (Beckman, 1982), while dissolved oxygen depletion rate was determined using the method of Bauer, Seidler and Knittel (1981). Heavy metals (copper, cadmium, and zinc) were prepared from ACS reagent grade chloride salts dissolved in deionized water, water soluble fractions of aldrin, dieldrin and endrin from reagents supplied by Chem Service, Westchester, Pennsylvania and the EPA Repository for Toxic and Hazardous Materials. Aldrin (6-152), dieldrin (6-115a) and endrin (5-171) supplied by Chem Service were $99 \%$ pure, and the reference analytical standards supplied by the EPA repository for aldrin, dieldrin, endrin, chiordane, and heptachlor were certified to be $>97 \%$ pure (5000 $\pm 250 \mathrm{ug} / \mathrm{m}$ ? methanol). Dow 2,4-D acid was $94 \%$ pure, while their Esteron $99^{*}$ contained $2,4-D$ at a concentration of $0.485 \mathrm{mg} / \mathrm{ml}$.

Chemicals supplied by the EPA Repository were added to deionized water at their water solubilities (as identified in U.S. EPA Water-Related Environmental Fate of 129 Priority Pollutants (EPA 440/4-79-029a and b)). Aldrin, dieldrin and endrin supplied by Chem Service were added to deionized water at 10 times their water solubility, mixed with a magnetic spinbar for 48 hrs at $24 \pm 2^{\circ} \mathrm{C}$, and filtered through a 0.45 micron membrane filter prior to chemical analysis and bioassessment. Dow Esteron $99^{(5)}$ and 2,4-D were assayed at nomina? concentrations based on their respective water solubilities (Worthing 1979). Esteron was assayed as an emulsion in deionized water, while 2,4-0 was dissolved in alkaline ( $\mathrm{pH}>10.00$ with $\mathrm{NaOH}$ ) deionized water which was neutralized to $\mathrm{pH} 7.0$ with $\mathrm{HCl}$ prior to bioassessment. Concentrations in excess of water solubility for aldrin, dieldrin, endrin, 2,4-D and Esteron $99^{\circ}$ used in the earthworm and Microtox assays were prepared using Spectro grade acetone prior to assay. Control assays were run using 
soivent blanks. The EC50 response values (1.C50 for earthworms) for each of the chemicals investigated were obtained using methods in Porcella (1983).

Average EC50 chemical concentrations and respective coefficients of variation (CV) from replicate experiments conducted with each test organism and chemical in a subgroup are reported in Tables 1 - 3. Statistically significant differences in EC50 response to the chemicals within a subgroup were observed for several bioassay organisms. For example, zinc was significantiy $(P<0.01)$ less toxic to algae compared to copper and cadmium (Table 1$)$. In addition, variances were sometimes significantly different $(P<0.05)$ for repeated assays and a single species and chemical subgroup (e.g., zinc compared to cadmium for earthworms, zinc and copper for wheat root elongation; variance ratio test, Table 31 in Pearson and Hartley, 1962) regardless of whether a logarithmic transform was used or not. The fact that some mean EC50 differences and variances were significantly different (which indicates the bioassays can be usefu? in research studies designed to detect small differences due to metals) led us to summarize our data as ranges (Table 4). This presentation also facilitated a comparison of species response for all chemicals in each of the three subgroups, i.e., the range of both parameters (means and CV's) for the heavy metal (copper, cadmium and zinc), herbicide (2,4-D, Esteron $\left.99^{B}\right)$, and insecticide (a)drin, d"eldrin, endrin, chlordane, heptachlor) chemical subgroups in Tables 1-3, are summarized in Tabie 4.

Heavy Metals

When the EC50 or LC50 values obtained with each test organism for copper, cadmium and zinc are compared with literature values (Table 1), no important differences are evident. The data in Table 1 also show algae and Daphnia to be the most sensitive to copper, cadmium and zinc, followed (in decreasing sensitivity or increasing tolerance) by results from the Microtox, DO rate depletion, root elongation and earthwom bioassays. The CV ranges in Table 1 indicate that the Microtox bioassay generally resulted in EC50 estimates with low precision, while all other assays were generally less variabie (i.e., CV $<25 \%$ ). 
TABLE 1. Mean EC50 (mg/L), Coefficient of Variation, and Number of Bioassays for Several Species Using Copper, Cadmium and Zinc

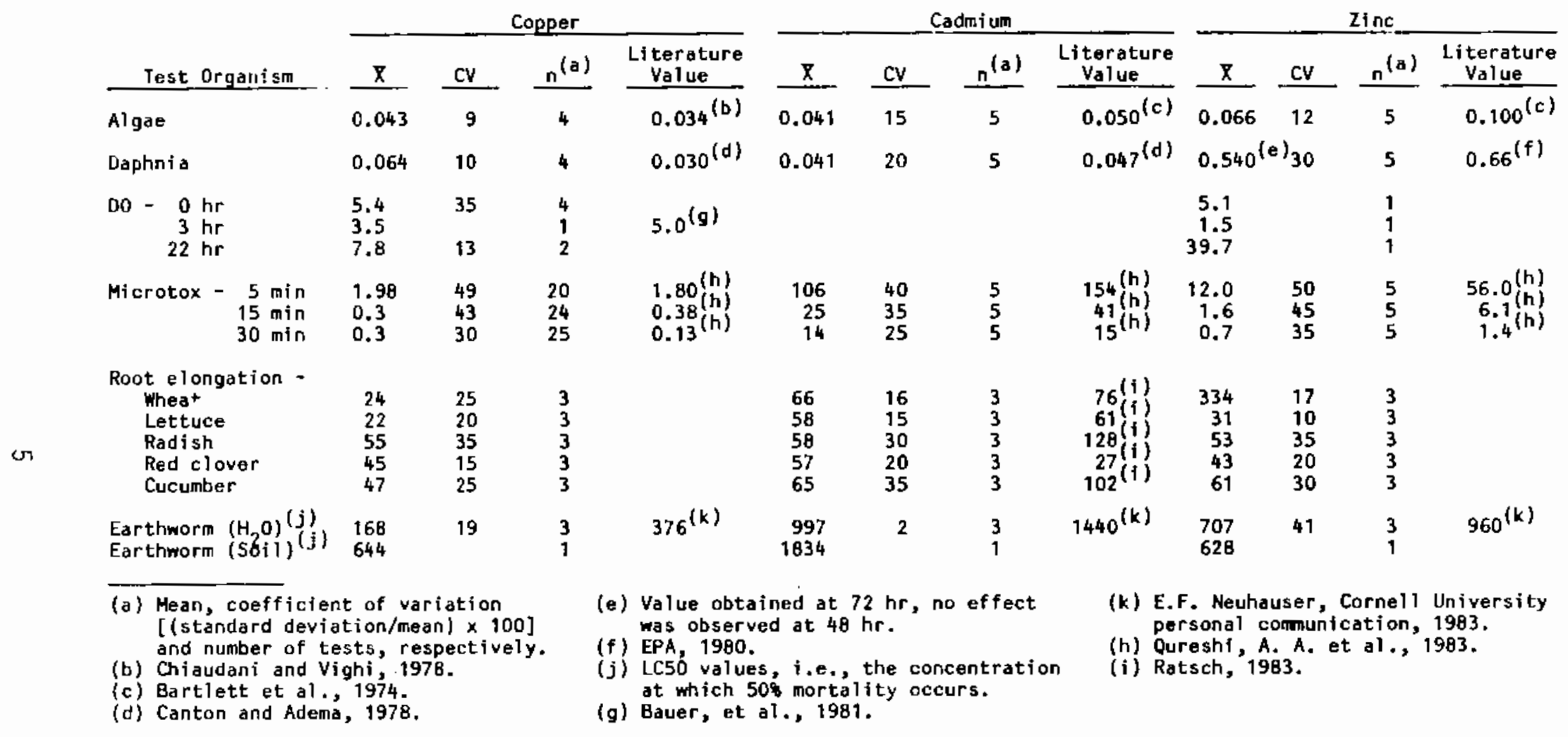


TABLE 2. Mean Bioassay EC50 (mg/L) Coefficient of Variation and Number of Bioassays for Two Herbicides

\begin{tabular}{|c|c|c|c|c|c|c|}
\hline \multirow[b]{2}{*}{ Test Organism } & \multicolumn{3}{|c|}{$2,4-D$} & \multicolumn{3}{|c|}{ Esteron $99^{\circ}$} \\
\hline & $x$ & $\mathrm{CV}$ & $n^{(a)}$ & $x$ & $\mathrm{CV}$ & $n$ \\
\hline Algae & 95.8 & 50 & 3 & 12.9 & 20 & 3 \\
\hline Daphnia & $>240$ & 40 & 3 & 13.1 & 25 & 3 \\
\hline $\begin{aligned} & D O- 0 \mathrm{hr} \\
& 3 \mathrm{hr} \\
& 22 \mathrm{hr}\end{aligned}$ & $\begin{array}{l}-- \\
--\end{array}$ & & & $\begin{array}{l}\because- \\
--\end{array}$ & & \\
\hline Earthworm $\left(\mathrm{H}_{2} \mathrm{O}\right)$ & NE & & & NE & & \\
\hline Earthwors (Acetone) ${ }^{(b)}$ & 9,830 & & 1 & 12,800 & 8 & 3 \\
\hline $\begin{array}{r}\text { Microtox - } 5 \mathrm{~min} \\
15 \mathrm{~min} \\
30 \mathrm{~min}\end{array}$ & $\begin{array}{l}112 \\
107 \\
128\end{array}$ & & & $\begin{array}{r}10.3 \\
7.7 \\
8.4\end{array}$ & & \\
\hline $\begin{array}{l}\text { Root elongation } \\
\text { Wheat } \\
\text { Lettuce } \\
\text { Radish } \\
\text { Red clover } \\
\text { Cucumber }\end{array}$ & $\begin{array}{r}0.7 \\
<0.1 \\
<0.1 \\
<0.1 \\
<0.1\end{array}$ & $\begin{array}{l}<10 \\
<10 \\
<10 \\
<10 \\
<10\end{array}$ & $\begin{array}{l}3 \\
3 \\
3 \\
3 \\
3 \\
3\end{array}$ & $\begin{array}{l}0.2 \\
<0.1 \\
<0.1 \\
<0.1 \\
<0.1\end{array}$ & $\begin{array}{l}<10 \\
<10 \\
<10 \\
<10 \\
<10\end{array}$ & $\begin{array}{l}3 \\
3 \\
3 \\
3 \\
3\end{array}$ \\
\hline
\end{tabular}

(a) Mean, coefficient of variation [(standard deviation/mean) $\times 100$ ] and number of assays; respectively.

(b) Reported as LC5O. Acetone was used to increase solubility.

NE - No biologically important effects.

\section{Herbicides}

Two formulations of the same herbicide, 2,4-D acid and Esteron $99^{*}$ $(44.9 \% 2,4-D)$, were used in bioassays. All seed species, except wheat, used in the root elongation assay (Tabie 2) exhibited EC50's $<0.1 \mathrm{mg} / \mathrm{L}$ of 2,4-D. Algae, on the other hand, were about 500 times less sensitive to 2,4-D. This is most likely due to the fact that $2,4-D$ is an auxin analog, which stimulates destructive growth in higher plants where growth is auxin regulated. Algae do not have auxin growth regulators, but react to inhibition of the photosynthesis energy transport process. Thus, as might be expected, the effects of 2,4-D on higher plants and algae differ markedly.

In our experiments, 2,4-D severely affected root elongation, while the algae, Microtox and Daphnia assays resulted in much higher EC50 values (Table 2). Earthworms tolerated the highest 2,4-0 concentrations which was similar to their response to heavy metals (Table 1). This rank order of sensitivity 
TABLE 3. Mean EC50 Values (mg/L) for Water Soluble Concentrations of Aldrin, Dieldrin, Endrin, Chlordane and Heptachlor from Chem Services, Westchester, Pennsylvania, and the EPA Repository of Toxic and Hazardous Materials

\begin{tabular}{|c|c|c|c|c|c|}
\hline Test Organism (a) & $\begin{array}{c}\text { Aldrin } \\
\text { (Chem Ser./EPA) }\end{array}$ & $\begin{array}{c}\text { Dieldrin } \\
\text { (Chem Ser./EPA) }\end{array}$ & $\begin{array}{c}\text { Endrin } \\
\text { (Chem Ser./EPA) }\end{array}$ & Chijordane $^{(b)}$ & Heptachlar (b) \\
\hline$A \lg a e^{(c)}$ & $.025 / .100$ & $.055 / .071$ & $.048 / .114$ & .156 & $.194^{(d)}$ \\
\hline Daphnia & $.025 / .094^{(e)}$ & $.079 / .107^{(\mathrm{e})}$ & $.051 / .112^{(f)}$ & $.165^{(g)}$ & $.162^{(h)}$ \\
\hline $\begin{array}{r}\text { DO - } 0 \mathrm{hr} \\
3 \mathrm{hr} \\
22 \mathrm{hr}\end{array}$ & $\begin{array}{l}--/ .079 \\
--/ \mathrm{NE} \\
--/ \mathrm{NE}\end{array}$ & $\begin{array}{l}\text { NE/NE } \\
\text { NE/NE } \\
\text { NE/NE }\end{array}$ & $\begin{array}{l}\text { NE/NE } \\
\text { NE/NE } \\
\text { NE/NE }\end{array}$ & $\begin{array}{l}.113 \\
\text { NE } \\
\text { NE }\end{array}$ & $\begin{array}{r}. \$ 29 \\
\text { NE } \\
\text { NE }\end{array}$ \\
\hline
\end{tabular}

(a) No biologically meaningful effects (NE) were observed for earthworms, Microtax or raot elongation. Single values resulted from EPA repository samples.

(b) Samples of Chlardane and Heptachlor mere not available from Chem Service.

(c) $n=3$ for all Daphnia and algae biosssays. See Table $t$ for the range of coefficients of variation.

(d) Literature value for heptachlor is 0.40 (U.S. EPA 440/5-80-079, 1980).

(e) Literature values for aldrin and dieldrin are 0.028 and 0.190 , respectively (Johnsan and Finley, 1980).

(f) Literature value for endrin is 0.352 (U.S. EPA 440/5-80-047, 1980).

(g) Literature value for ch?ardane is 0.058 (Randell, 1979).

(h) Literature value for heptachlor is 0.078 (Macek et al., 1976).

TABLE 4. Sumary of EC50 (mg/L) Results in Tables 1-3, for Heavy Metals, Herbicides and Insecticides for Six Bioassays

\begin{tabular}{|c|c|c|c|c|c|c|}
\hline \multirow[b]{2}{*}{ Test Organism } & \multicolumn{2}{|c|}{ Heavy MetaIs } & \multicolumn{2}{|c|}{ Herbicides } & \multicolumn{2}{|c|}{ insecticides (a) } \\
\hline & Means & CV Range $(b)$ & Means & CV Range & Means & CV Range \\
\hline Algae & $0.04-0.07$ & $9-15$ & $13-96$ & $20-50$ & $0.07-0.19$ & $10-30$ \\
\hline Daphnia & $0.04-0.54$ & $10-30$ & $13->240$ & $25-40$ & $0.09-0.17$ & $10-40$ \\
\hline Do rate $3 \mathrm{hr}$ & $1.5-3.5$ & & +- & & & \\
\hline Microtax $30 \mathrm{~min}$ & $0.3-106$ & $25-35$ & $8-128$ & & & \\
\hline Root elongation & $22-334$ & $10-35$ & $<0.1=0.7$ & $<1-10$ & & \\
\hline $\begin{array}{l}\text { Earthworm }\left(\mathrm{H}_{2} \mathrm{O}\right)^{(\mathrm{c})} \\
\text { Ear thworm (Acetone) }\end{array}$ & $168-997$ & $2=41$ & $9830-12800$ & $=-8$ & $5000-16000^{l}$ & \\
\hline
\end{tabular}

(a) Based on chemicals obtained from the EPA repository for toxic and hazardous material.

(b) $\mathrm{CV}=$ coefficient of variation [ (standard deviation/mean) $\times 100]$.

(c) LC50 values, i.e., the concentration at which 50 mortality occurs.

(d) Erratic results (not 1 isted in Table 3) where water soluble studies are reported. 
to 2,4-D is quite different from that observed with heavy metals where the root elongation assay resuited in the second highest tolerance.

Comparison of the response of the test organisms to Esteron $99^{\circ}$ (a commercial formulation wich contains 44.9\% 2,4-0 and undisciosed "inert" ingredients) and the response obtained using 94\% pure 2,4-D acjd (TabTe 2) shows that Esteron $99^{\circ}$ is significantly more toxic to algae, Daphnia, and Microtox. There was very little difference in root elongation response for the five plant species tested. Daphnia and algae EC50 values were similar for Esteron $99^{\circ}$ but were 18 and 7.4 times more sensitive to Esteron $99^{\circ}$ than to 2,4-D acid respectively (Table 2). The higher toxic response for Esteron $99^{2}$ suggests that the "inert" components in the formulation are also active toxicants, or that the sample preparation process somehow affected bioavailability.

Insecticides

Water soluble solutions of aldrin, dieldrin and endrin were prepared from reagents supplied by Chem Service (dry powder) and the EPA repository of toxic and hazardous materials (in methanol). The resulting solutions were bioassayed (using HMAT organisms) in order to determine whether the same chemical (similar purities $>97 \%$ ) obtained from two sources produced the same response in test species. Toxic responses to botin water soiuble formutations of aldrin, dieldrin and endrin were only evident for algae and Daphnia (Table 3).

The algae and Daphnia EC50 values for assays using EPA repository aldrin and endrin (Table 3) are higher than the EC50 va"ues for the same insecticides supplied by Chem Service even though EPA formulations produced higher concentrations of the active ingredient. The active ingredients are present in higher concentrations in the EPA repository formulations (Table 5) because the EPA methanol formulation was more soluble in water than the Chem Services powder. Only slightly higher EC50 values were found for dieldrin. Methanol added to solutions (.005\% methanol $v / v)$ of algal assay medium and Daphnia test water (200 $\mathrm{mg} / \mathrm{L}$ hardness) did not adversely c.ffect either test organism 
TABLE 5. Concentrations of Aldrin, Die\}drin, Endrin, Chlordane and Heptachlor $(\mathrm{mg} / \mathrm{L})$ in Water Soluble Assay Samples. (Stock samples supplied by Chem Service and the EPA Repository of Toxic and Hazardous Materiais.)

\begin{tabular}{lcc} 
& & \multicolumn{2}{c}{ Source } \\
\cline { 2 - 3 } Constituent & Chem Service & EPA Repository \\
Aldrin & 0.025 & 0.125 \\
Dieldrin & 0.096 & 0.130 \\
Endrin & 0.069 & 0.142 \\
Chlordane & --- & 0.206 \\
Heptachlor & --- & 0.197
\end{tabular}

at the maximum methanol concentrations in water soluble assay medium when EPA repository insecticide samples were assayed.

\section{DISCUSSION}

Our results suggest that algae and Daphnia are the most sensitive to heavy metals, followed in order of decreasing sensitivity by $D 0$ rate depletion, Microtox, root elongation and earthworms (Table 1). As expected, root elongation was most affected by the herbicide 2,4-D, followed in increasing order of tolerance by algae and Microtox, Daphnia and earthworms (Table 2). Algae and Daphnia were the only organisms sensitive to the insecticides tested (Table 3 ). These results indicated that algae might be the most broadly sensitive test organism for assays using soil elutriates and water samples, since they responded to water solutions of the major chemical subgroups we studied. A larger group of chemicals must be tested to substantiate this finding. The differential response observed for 2,4-D acid and Esteron $99^{\circ}$ illustrates the value of bioassays in identifying additional (or perhaps synergistic) biotoxic components in chemical mixtures. In addition, these results indicate that a potential problem may exist if toxic effects are predicted "for pure chemicals based on results using commercial formulations (or vice versa). Based on its 2,4-D content, the Esteron 2,4-D 
preparation used in our studies should have had minimal effects on aquatic organisms. However, laboratory bioassays of this commercial formulation (as it would be used in the field) indicate the material may be more toxic than its active ingredient. The Tower EC50's obtained using the Chem Service a]drin and endrin suggest the presence of a toxic constituent not present or bioactive in the EPA chemical reference standards. These resuits demonstrate the ability of algae and Daphnia to define differences in chemical toxicity due to formulation differences and reinforce the speculation that inert components might themselves be toxic or synergistic. Based on our results using pure chemicals it appears that one value of using a multi-media bioassessment protocol is that the change in tolerance levels of test organisms to different toxicants can be observed. This information can be used to identify those ecosystem components most susceptible to the presence of a toxicant, regardless of its specific chemical characteristics. 


\section{TOXICITY OF CHEMICAL WASTE SITE SAMPLES}

\section{INTRODUCTION}

A study using soijs, soil elutriates, and water samples from the Rocky Mountain Arsenal (RMA) and seven other hazardous waste sites was initiated to ascertain if the HMAT test organisms and the modified Neubauer seed germination test (Thomas and Cline, 1984, accepted for publication in Environmental Toxicology and Chemistry), would respond to the unknown chemical mixtures contained in these samples. The Neubauer test was added to the HMAT series because the earthworm soil contact test was not very sensitive in our research on pure chemicals. Addition of this assay allowed a better intercomparison of the toxic properties of elutriates and the soils themselves. Because of the high salt content of Basin $F$ water samples from the RMA, preliminary wheat and lettuce seed germination bioassays were conducted (Thomas and CTine, 1984, accepted for publication in Environmentâ? Toxicology and Chemistry) which showed that copper, sodium nickel or arsenic, alone or in combination were not toxic at levels found in Basin water used in these studies.

\section{RESULTS}

\section{Rocky Mountain Arsena}

Bioassays of soil elutriates from site 085 at RMA (Figure 2 for sample location; see Figure 1 for RMA location) show that the assay using algae was approximately 10 fold more sensitive than the Daphnia assay (Table 6). No response was observed for Microtox and lettuce root elongation (RE), while the earthworm soit test for sample 085 had an LC5D value $>25 \%$ soil. Such results are typical of those for low levels of heavy metais (Table 2). In contrast, soil sample 092 (from the Basin A 1 ime pit, section 36, Figure 1) shows a different and increased toxicity pattern for Daphnia, Microtox, RE and earthworms, suggesting a stronger influence from the organic components in this sample. Both the Basin $F$ waste water (a holding basin for toxic wastes) and a sample of Basin $F$ well water (well number 26008 located in 
TABLE 6. EC50 Response or Percent Inhibition Caused by Chemical Contaminants in Rocky Mountain Arsenal Soil, Soil Elutriate, Waste Water and Groundwater Samples

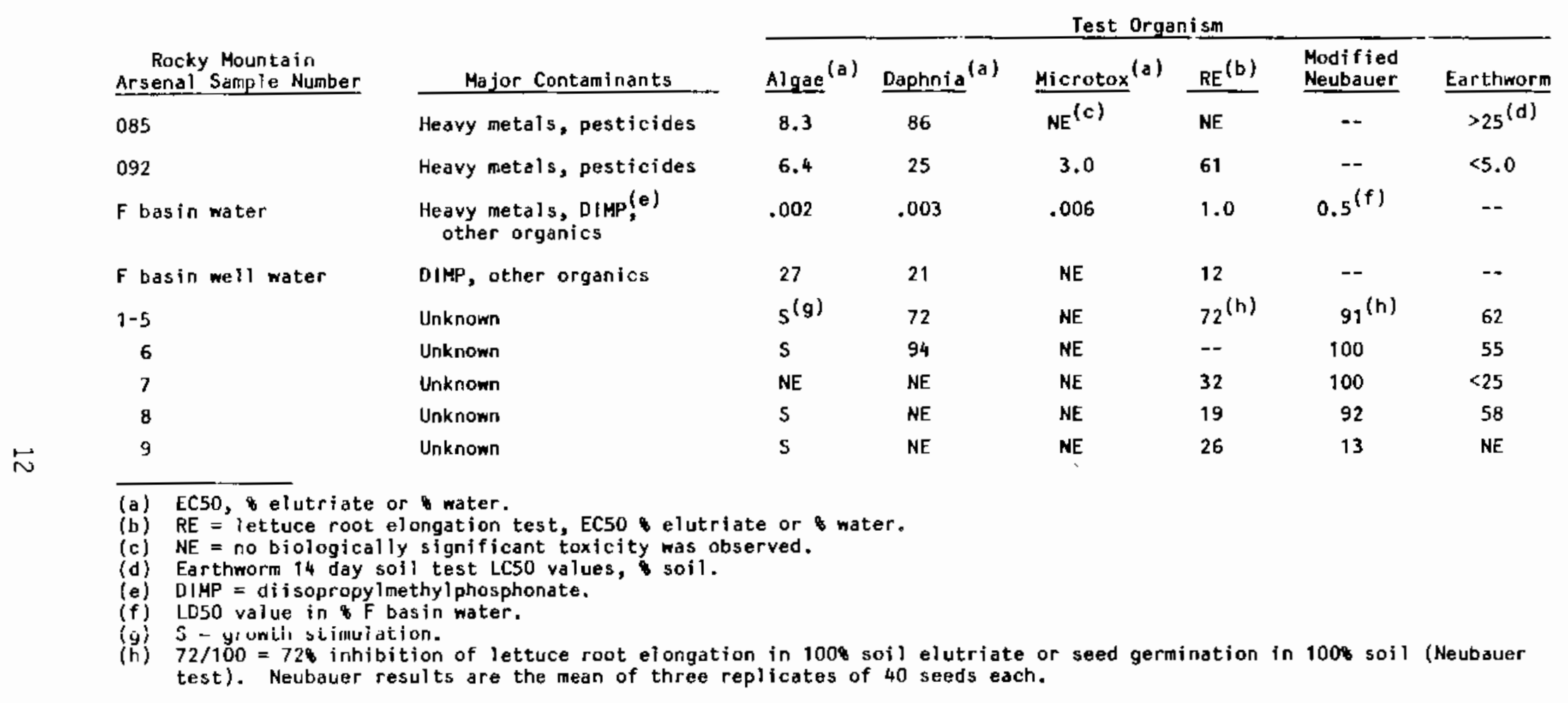




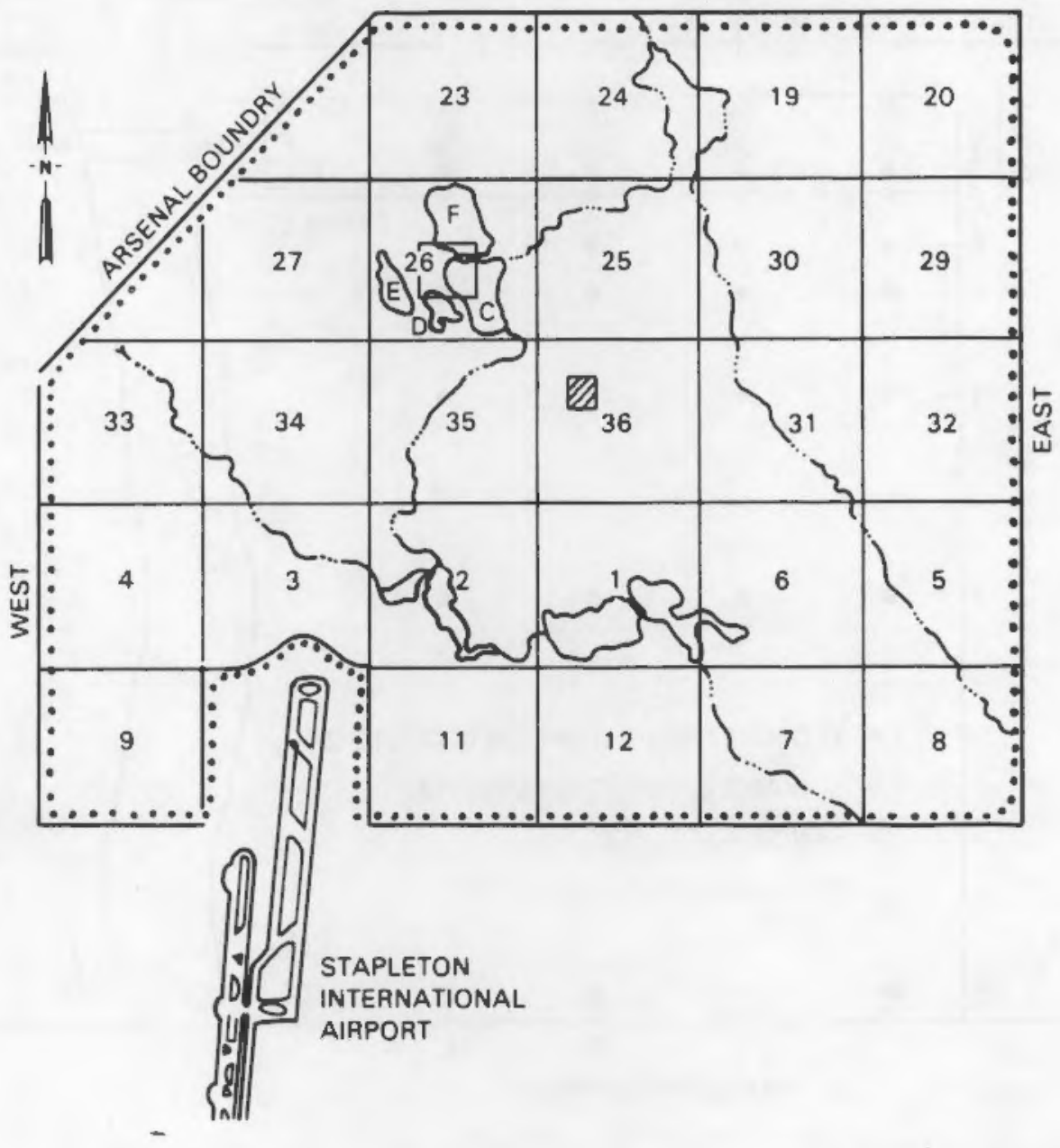

FIGURE 1. Location of the Study Site in Basin A (Section 36) at the Rocky Mountain Arsenal. The areas in section 26, labeled C, D, E and F are or were waste ponds.

section 26, Figure 1) were toxic to most HMAT organisms tested. Basin F water was toxic to all organisms tested with EC50 values $<1.0 \%$ dilution, while $F$ basin well water was much less toxic to algae, Daphnia and RE, and was not toxic at all to the Microtox assay. The assay results for RMA soil elutriate samples from samples 1 to 9 (upper right in Figure 2) are unique in that, except for site 7 , these soil elutriates caused algal growth stimulation, rather than growth depression. This lack of an algal toxic response 


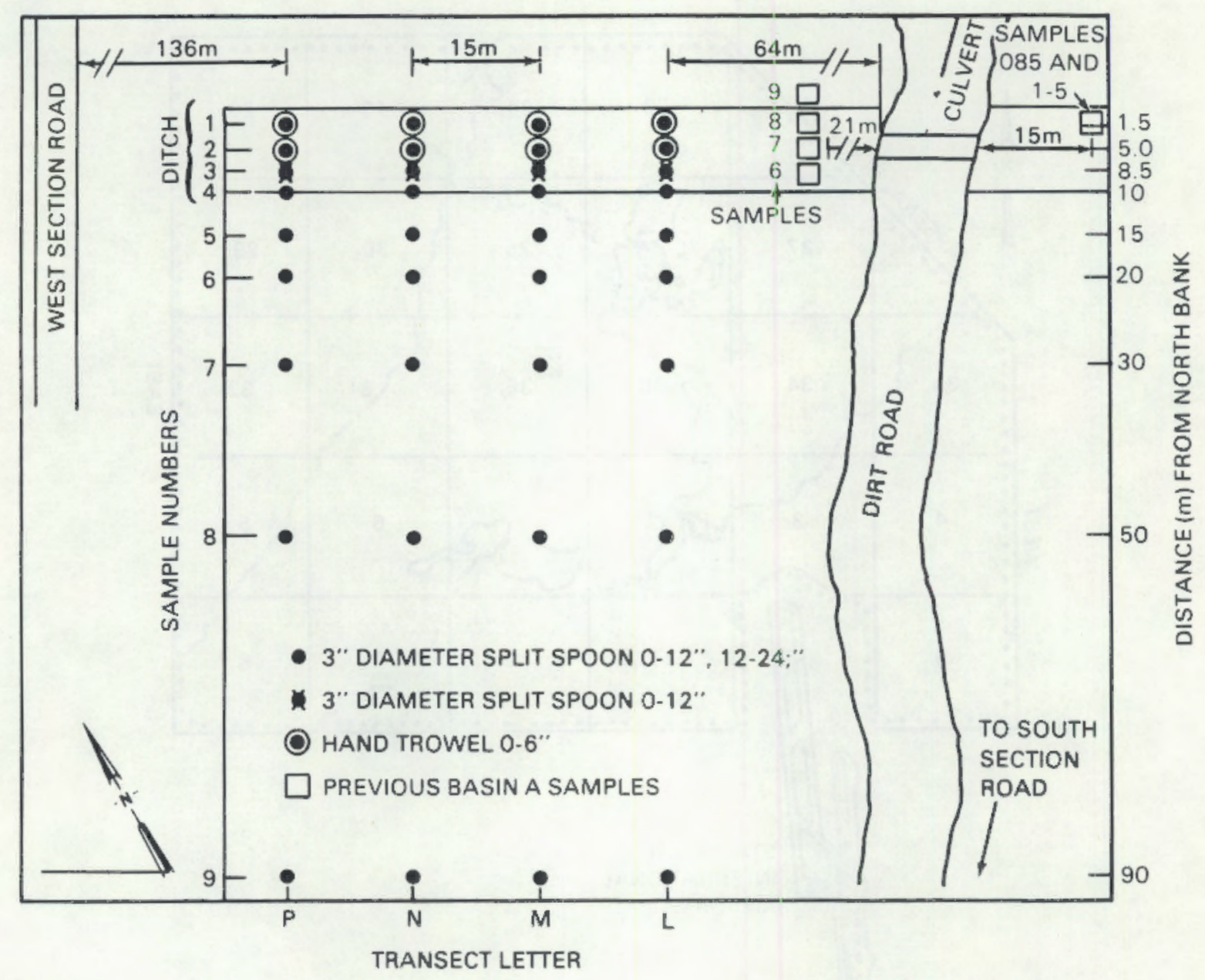

FIGURE 2. Location of Soil Sampling Points in Basin A (Section 36) at the Rocky Mountain Arsenal

was partially corroborated by the results of the Daphnia, assays which show an EC50 of $72 \%$ elutriate dilution for samples 1-5 (subsamples of a single large sample collected adjacent to 085, but one year later) and site 6 (EC50 of $94 \%)$. In contrast, lettuce root elongation results show that $100 \%$ soil elutriates are toxic, with samples 1-5 being most toxic.

The earthworm and modified Neubauer soil contact bioassays for the same RMA samples confirm some of the lettuce root elongation results and, unlike the other soil elutriate tests, show the presence of bioactive toxicants at 
TABLE 7. EC50 Response ( $\%$ Soit for the Earthworm Test) to Chemical Contaminants in Hazardous Waste Site Soil and Soil

ETutriate Samples

Test Organism

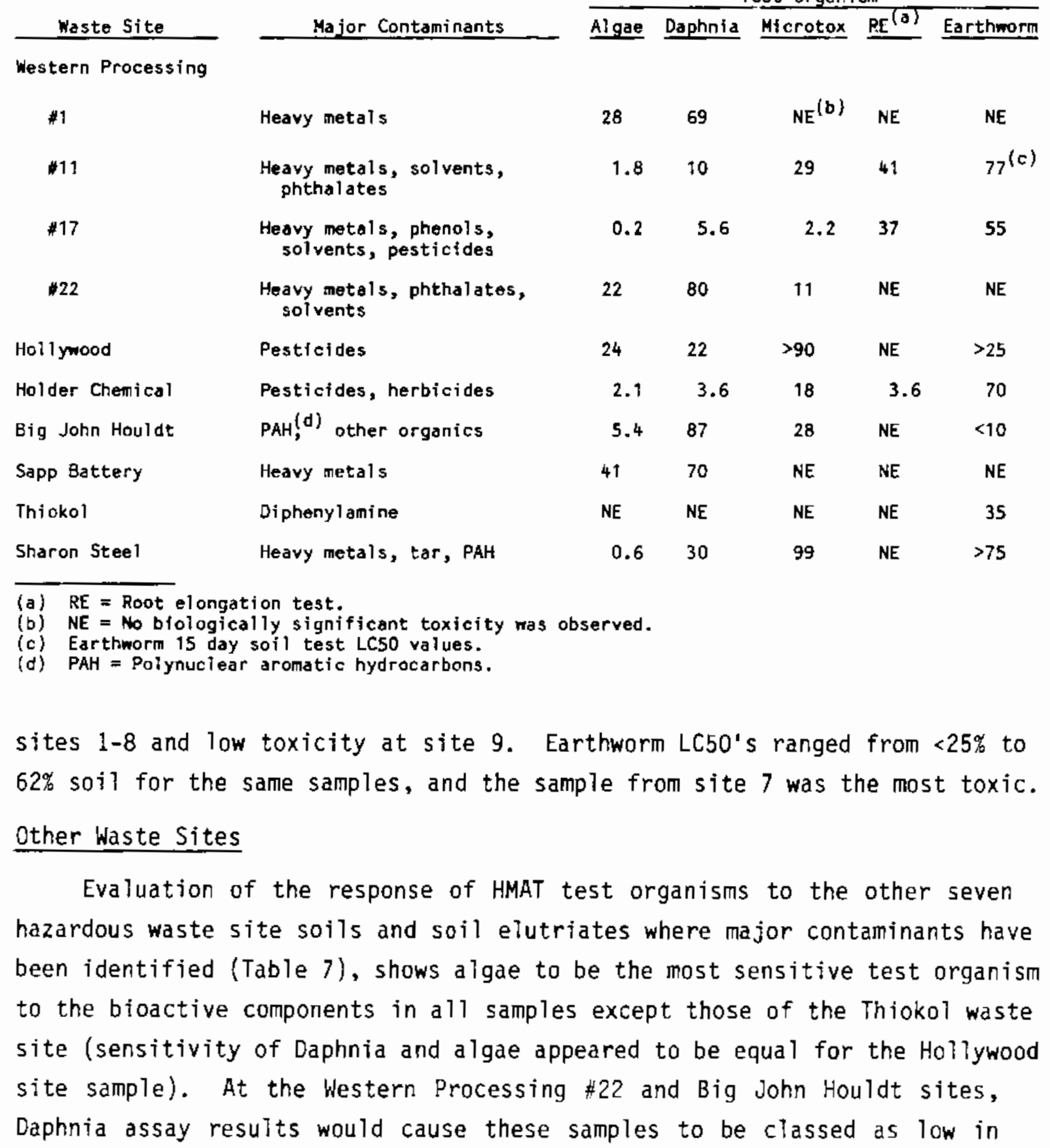


toxicity potential (Porcella (1983) uses low, moderate, moderately high, and highly toxic to describe EC-50 values $>75 \%, 50-75 \%, 25-50 \%$, and $<25 \%$ elutriate dilution, respectively), whereas the algae assay results can be interpreted as giving a highly toxic response. Microtox assay results confirm the highly toxic nature of the Western Processing \#22 elutriate, but the Microtox assays were insensitive to the samples from the Western Processing \#1, Sapp Battery and Thiokol sites. The lettuce root elongation test was the least sensitive to soil elutriate samples from these seven waste sites. With the exception of the Thiokol site, the earthworm soil test was usually less sensitive than algae and Daphnia elutriate assays, but generally gave results corresponding to those of the root elongation and Microtox tests.

We previously established that the root elongation, Microtox and earthworm tests are not very sensitive to three heavy metals (Table 1). Based on the assays of Western Processing \#11 and \#22 soils, it appears that the earthworm assay may not be affected by phthalates. However, earthworms were the only test organism to respond to the major chenical, diphenylamine, in the Thiokol soil sample. Unilike most of the RMA samples and the Thiokol sampie, the other seven waste site soil elutriates apparently contained toxic water soluble chemicals. The algat assay is sensitive to these water soiuble components. Based on this assay alone, five of the seven sites would have been deemed highly toxic (EC50 values ranging from 0.2 to $22 \%$ ), the Sapp Battery sample would be moderately toxic and the Thiokol elutriate would be designated non-toxic (the earthworm assay suggests that this sample is moderately toxic).

\section{DISCUSSION}

A comparison of the soil elutriate and earthworm and iettuce seed soil contact assay resuits based on RMA sampies suggest: 1) that these soils contain very low levels of water soluble heavy metal and pesticide contaminants; 2) that if the heavy metais are soluble they are bound to organic compounds which chelate them so that they are not bioactive, and thus are not toxic to algae, Daphnia and Microtox; 3) that the water soluble toxic components in these soils are leached as a function of time or are strongly adsorbed to the 
clay and organic fractions, but are available to earthworms and lettuce seeds; or 4) disappeared during preparation or testing of elutriates.

We believe that the results, based on bioassays from seven additional waste sites, offer an initial validation of our test protocol premise that a group of diverse bioassays is preferable to any single test and that the response of specific organisms can aid in identifying which ecological compartments may be impacted by known or unknown chemical wastes. Although we were able to rank these specific waste site soil samples, the extent of toxicity cannot be ascertained without intensive field sampling. 



\section{FIELD STUDY}

To demonstrate the utility of bioassays in chemical hazard assessment, we conducted a field study at RMA in Comerce City, Colorado. The site had been used for the manufacture of antipersonnel gases, herbicides, and insecticides, and as an ordinance testing area. Over the years a myriad of organic and inorganic compounds were carried through ditches to a series of interconnecting holding basins for disposal. Complete chemical characterization of the site would be very expensive, and this situation offered an excellent bioassay opportunity. Previous lettuce seed bioassay results using RMA soil samples (Table 6) led us to believe that an area near a former waste trench was contaminated. Results from the other bioassays showed less or no toxicity.

\section{STUDY SITE}

The waste trench chosen for study at the arsenal is located in Basin A (Figure 1). Previous data indicated a possible gradient of contamination on the west side of section 36, extending north-south from the trench. Thus, four parailel transects were estabiished on the west side of the basin, each beginning on the north bank of the trench and running south for 290 (Figure 2). A logarithmic scale was used beyond the south trench edge to locate nine sample points on each transect ( 36 cores, 60 total samples; see below) because we thought contamination might have moved by some physical means (e.g., wind or water). The transects were $15 \mathrm{~m}$ apart and labeled $L, M, N$ and P. The first three sample points of each transect fell within the trench, and the fourth was on the top of the south bank. Samples 5 through 9 were located south of the north trench edge at $15,20,30,50$ and $90 \mathrm{~m}$, respectively (Figure 2).

\section{SOIL SAMPLING}

At most sampling points, a split spoon corer mounted on a hydraulic drill rig was used to take two soil cores, one from 0 to $15 \mathrm{~cm}$ depth, and a second from 15 to $30 \mathrm{~cm}$. Each core was $7.5 \mathrm{~cm}$ in diameter and together the 
two cores weighed approximately $4 \mathrm{~kg}$. Between sampling points, the split spoon and drill bit were decontaminated by washing with methanol and rinsing with distilied water. All samples were put in plastic bags, sealed and labeled. The area being sampled and any problems encountered (e.g., mud, accessibility) dictated exactly how the cores were taken and any variations on the basic sampling scheme.

For example, the first two points in each transect were in the trench, which was very wet and soft, and the samples from these points were difficult to obtain. Since it was impossible to sample by depth, two surface samples (to $15 \mathrm{~cm}$ deep) were taken from these points with a hand trowel. Sample points $L, N$ and P-3 were just over the south bank of the trench and could not be reached from the drill rig. At these points, the split spoon was hammered into the ground and extracted by hand. Only a 0-15 cm sample was obtained from each of these points; the soil from $15 \mathrm{~cm}$ to $30 \mathrm{~cm}$ was too wet to stay in the split spoon. A surface sample of undefined depth was taken from $M-3$ since the entire profile was very wet. Samples 4 through $g$ in each transect were abtained using the drilt rig as discussed above. On arrival at our laboratory, the samples were air dried and sieved through a in. screen.

\section{PHYTOASSAY OF SOIL}

We elected to use lettuce seeds exclusively in the phytoassays because our prior results showed that they are more sensitive than other seeds. The mortalities (mean of three subsamples from each core fraction) observed at points 1-3 in each transect were based on the sarte soil sample and could be considered a measure of experimental reproducibility, since subsamples from these three points were assayed in two different experiments (i.e., the 0-15 cm fractions were run as one experiment and the $15-30 \mathrm{~cm}$ samples were assayed two weeks later, Table 8). The maximum mortality difference between the subsamples in these two experiments was about $15 \%$ seeds of 40 , sample P-3) for samples which were reassayed (control and samples 1-3, all transects). Thus, if mortality differed by $>15 \%$, as a function of depth, we considered the differences real. Using this rule, only sample (L7) in either transect $L$ or $N$ showed any lettuce seed mortality difference attributable to 

TABLE 8. Comparison of Mean Percent Lettuce Seed Mortality in $9-15 \mathrm{~cm}$ (Experiment 1)
and $15-30 \mathrm{~cm}$ (Experiment 2) Fractions of Basin A Soil

\begin{tabular}{|c|c|c|c|c|c|c|c|c|c|c|c|}
\hline \multicolumn{3}{|c|}{ I. } & \multicolumn{3}{|c|}{ M } & \multicolumn{3}{|c|}{$\mathbf{N}$} & \multicolumn{3}{|c|}{$P$} \\
\hline $0-15, \mathrm{~m}$ & $(b \longdiv { 1 5 - 3 0 }$ & $\mathrm{cm}^{(b)}$ Difference & $0.15 \mathrm{~cm}$ & $15-30 \mathrm{~cm}$ & Difference & $0-15 \mathrm{~cm}$ & $15-30 \mathrm{~cm}$ & Difference & $0.15 \mathrm{~cm}$ & $15-30 \mathrm{~cm}$ & Difference \\
\hline $100^{(c)}$ & 100 & 0 & 100 & 100 & 0 & 83 & 79 & +4 & 100 & 100 & 0 \\
\hline 100 & 100 & 0 & 100 & 100 & 0 & 100 & 100 & 0 & 100 & 100 & 0 \\
\hline 86 & 78 & +8 & 91 & 78 & +13 & 97 & 98 & -1 & 76 & 91 & -15 \\
\hline 10 & 22 & -11 & 11 & 83 & -72 & 92 & 100 & -8 & 15 & 96 & -81 \\
\hline 14 & 12 & +2 & 19 & 16 & +3 & 13 & 9 & +4 & 15 & 66 & -51 \\
\hline 100 & 100 & 0 & 32 & 100 & -68 & 100 & 100 & 0 & 97 & 100 & -3 \\
\hline 11 & 36 & -25 & 8 & 50 & -42 & 98 & 95 & +3 & 100 & 100 & 0 \\
\hline 14 & 20 & -6 & 17 & 29 & -12 & 7 & 10 & -3 & 6 & 100 & -94 \\
\hline 12 & 15 & -3 & 14 & 65 & -51 & 42 & 52 & -10 & 22 & 13 & +9 \\
\hline
\end{tabular}

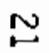

$0-15 \mathrm{~cm} \quad 15-30 \mathrm{~cm}$ Difference

21

13

$+8$

(a) Subsampies of PNML 1-3 $(0-15$ and $15-30 \mathrm{~cm})$ and control were from the same source in each experiment.

(b) Sotil samples from 0-15 cm and $15-30 \mathrm{~cm}$ were run as separate experiments two meeks apart.

(c) Mean 8 of three replicate dishes of 40 seeds each. The average standard deviation for treatments with seeds that germinated was 3.12 seeds for the $15-30 \mathrm{~cm}$ soils and 2.29 seeds for the $0-15 \mathrm{~cm}$ fraction. Details of the assay are in Thomas and $\mathrm{Cline}, 1984$. 
depth. However, four samples in transect $M$ and three in transect $P$ showed differences greater than $15 \%$ mortality, suggesting that the contaminants had either migrated below $15 \mathrm{~cm}$ or were purposely placed there. We found no records to support the iatter argument and conclude that the toxic material had migrated.

\section{RESULTS FROM OTHER BIOASSAYS}

The results for all other HMAT bioassays conducted on Basin A soils are in Table 9. Sample availability either precluded analyses or curtailed the number of assays that could be conducted. Daphnia or Microtox bioassay results are not included because no response was observed in 10 and 36 assays, respectively.

Resuits from the algat assay revealed that sinall quantities of elutriate from all but four samples were stimulatory (5C20). The four eiutriate samples which inhibited algae were obtained on or very near the waste trench on transects $L$ and $N$. According to the criteria outlined in Porcella (1983) these sites would be classified as moderately toxic. Interestingly, only $1 \%$ to $14 \%$ elutriate from transect $M$ samples was needed to stimulate algal growth. Based on the algal bioassay results, we conclude that the toxic components detected using lettuce seeds (Table 8), were probably not water soluble heavy metais, herbicides or insecticides (except perhaps sites $[(2-4)$ and N2) since our results using pure chemicals (Tables 1-3) showed depressed algat growth in the presence of these contaminants.

Results of the earthworm bioassay are presented as a function of lettuce seed mortality in Figure 3. Except for plot P3 soil, earthwoms are severely affected when placed in Basin $A$ soil sampies where lettuce seed mortalities are over $70 \%$. In contrast, the five soil samples which caused 20 to $70 \%$ lettuce seed mortality resulted in no earthworm deatrs. Thus, for these Basin A samples, it appears either that lettuce seeds are more sensitive to lower levels of a toxic component that does not affect earthworms, or that earthworms are more resistant to the same toxicant. 
TABLE 9. Intercomparison of lettuce root elongation (RE), Lettuce Seed Mortality (MN), Earthworm mortality (EW) and Algal Inhibition (S) for Two Fractions of Basin A Soils Obtained from the Rocky Mountain Arsenal

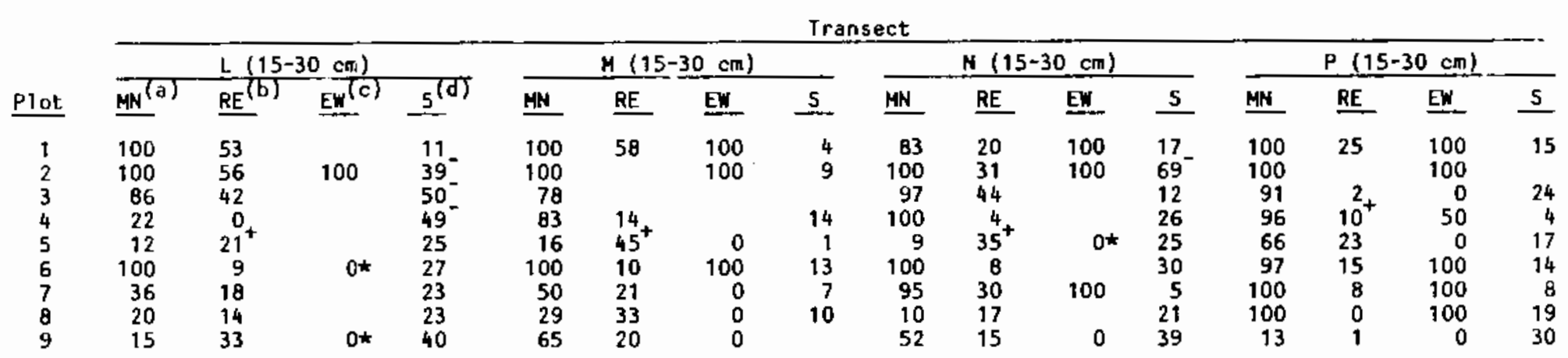

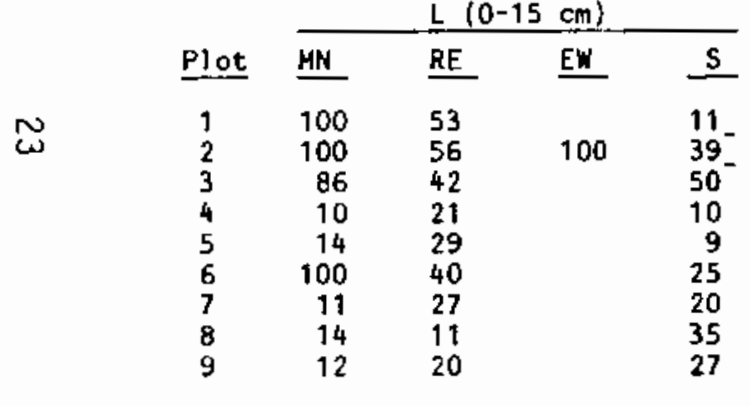

(a) Fercent lettuce seed mortality. Each value is the mean mortality of three replicate plates of 40 seeds each grown in soil.

(b) Percent of control lettuce root length (based on soil elutriate). Values accompanied by a plus (+) were greater than controls.

(c) Earthworm percent mortality using 1008 soil (one replicate of 10 earthworms). Values with an asterisk ( $\star$ ) are questionable since soils had been previously used to prepare elutriates.

(d) EC50 values in elutriate are denoted by a minus (-), while values with no superscript were stimulatory (SC20), 


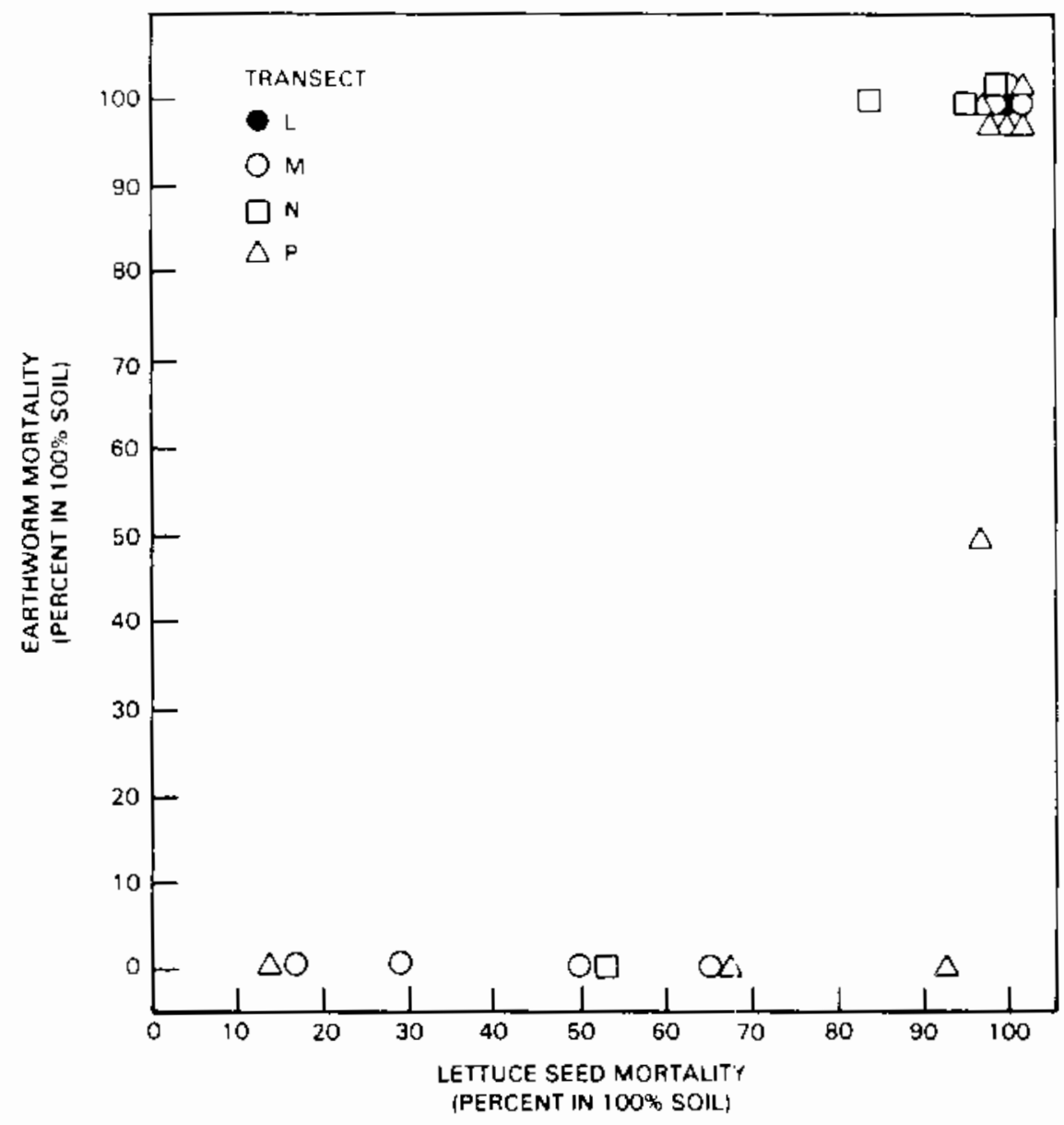

FIGURE 3. A Comparison of Earthworm and Lettuce Seed Mortality Using Basin A Soils from Rocky Mountain Arsenal

Results from the lettuce root elongation (based on elutriates) and the lettuce seed mortality (based on intact soil) bioassays are compared in Figure 4. There appears to be little correlation, perhaps with the exception of samples from Transect $L$. Bioassay results from Transect $P$ samples indicate that high lettuce seed mortalities are accompanied by about $\pm 15 \%$ change in root elongation (i.e., no correlation at a 11). Thus, the phytotoxic component that impairs lettuce seed germination eitrer is not water soluble or does not affect root elongation. As expected (based on Figures 3 and 4 ), the results of earthwom mortality and lettuce root elongation are not correlated (Figure 5). 


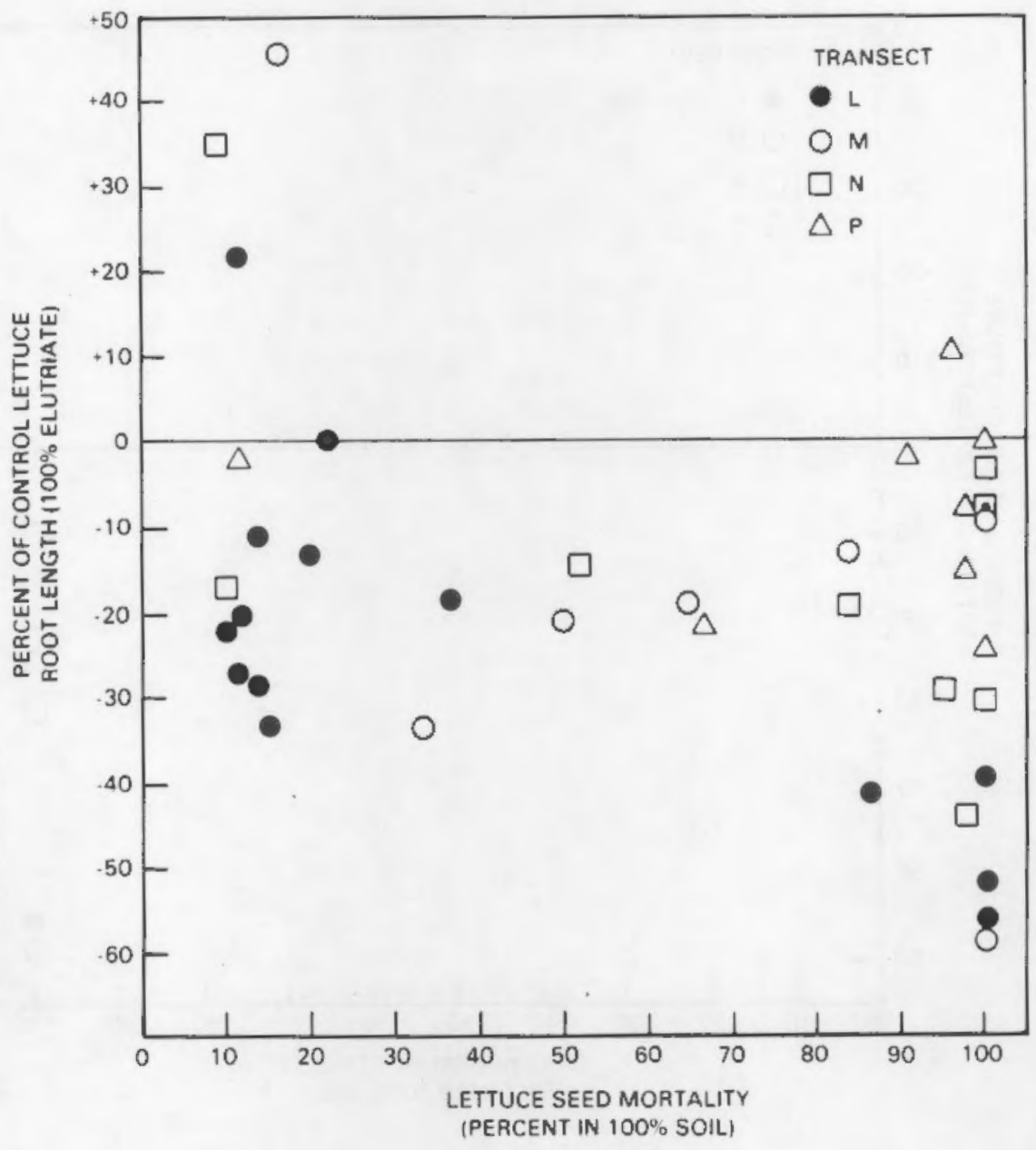

FIGURE 4. A Comparison of Lettuce Root Elongation and Lettuce Seed Mortality Using Basin A Soils from Rocky Mountain Arsenal

\section{CLEANUP DECISION BASED ON BIOASSAYS AND KRIGING}

One way to depict the lettuce seed mortality patterns at each depth (Table 8 ) is to devise a contour map, based on the observations. We prepared a map of lettuce seed mortality using a relatively new statistical technique called kriging, developed for use in the mining industry and used principally in Europe and South Africa (Journal and Huijbregts 1978, Clark 1؟82). Kriging is a weighted, moving average technique to calculate point estimates or block averages over a specified grid. The derivation of the kriging 


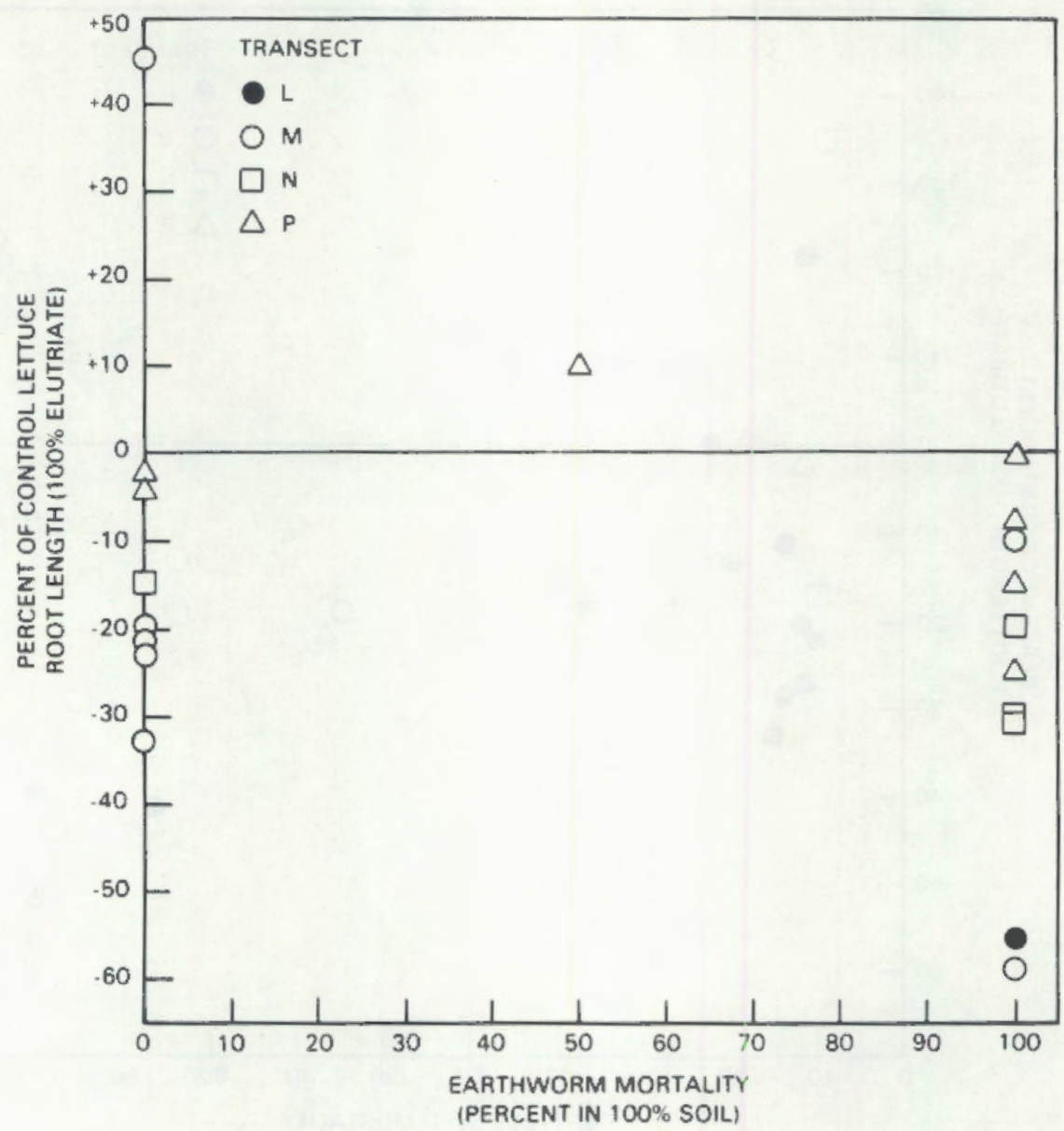

FIGURE 5. A Comparison of Lettuce Root Elongation and Earthworm Mortality Using Basin A Soils from Rocky Mountain Arsenal

weights takes into account the proximity of the observation to the point or area of interest, the structure of the observations (i.e., the relationship of the squared difference between pairs of observations and the intervening distance between them) and any systematic trend or drift in the observations. Additionally, kriging provides a variance estimate that can be used to construct a confidence interval for the true value. Contour maps are prepared from the kriging estimates. Our results, presented in Figures 6 and 7 , clearly show the lettuce szed mortality differences at the two depths. Estimated contamination is greater at $15-30 \mathrm{~cm}$ than at $0-15 \mathrm{~cm}$. This is also indicated by our qualitative analyses of results in Table 8. 


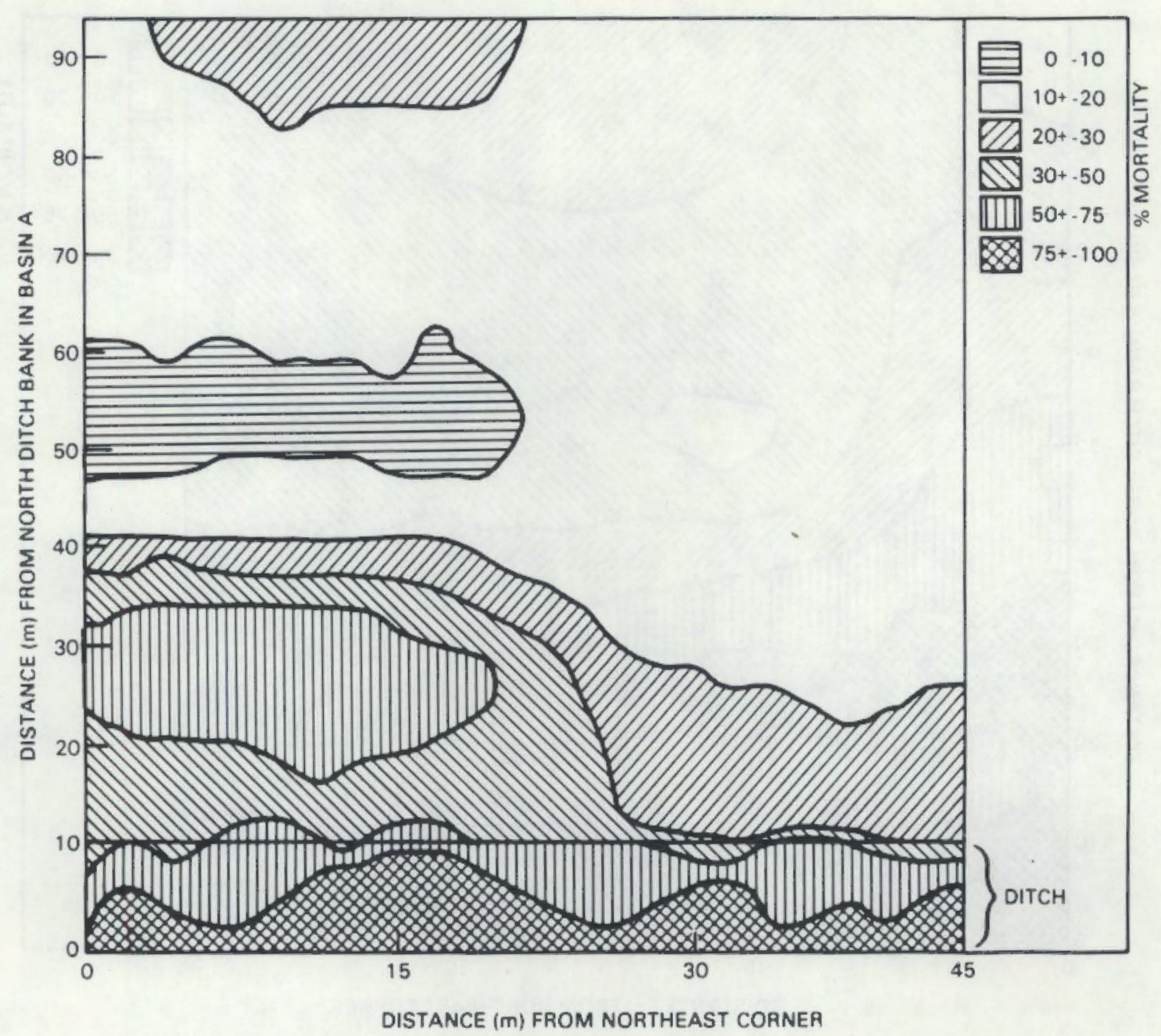

FIGURE 6. Estimated Lettuce Seed Mortality (Based on Kriging) for the 0-15 cm Soil Fraction from the Rocky Mountain Arsenal

We believe that such maps could be useful in site cleanup decisions. As a possible scenario, we have selected $30 \%$ lettuce mortality as a criterion for cleanup of this Basin A site (Figures 8 and 9). The areas enclosed by the solid lines would be targeted for cleanup. Unfortunately, the cleanup decision would be different for the $0-15 \mathrm{~cm}$ (Figure 8 ) and the $15-30 \mathrm{~cm}$ (Figure 9) fractions. While this difference complicates decision making, the available data (Table 8 ) and the kriging maps (Figures 6 and 7 ) show that the field situation is complex, and that cleanup decisions based solely on either 


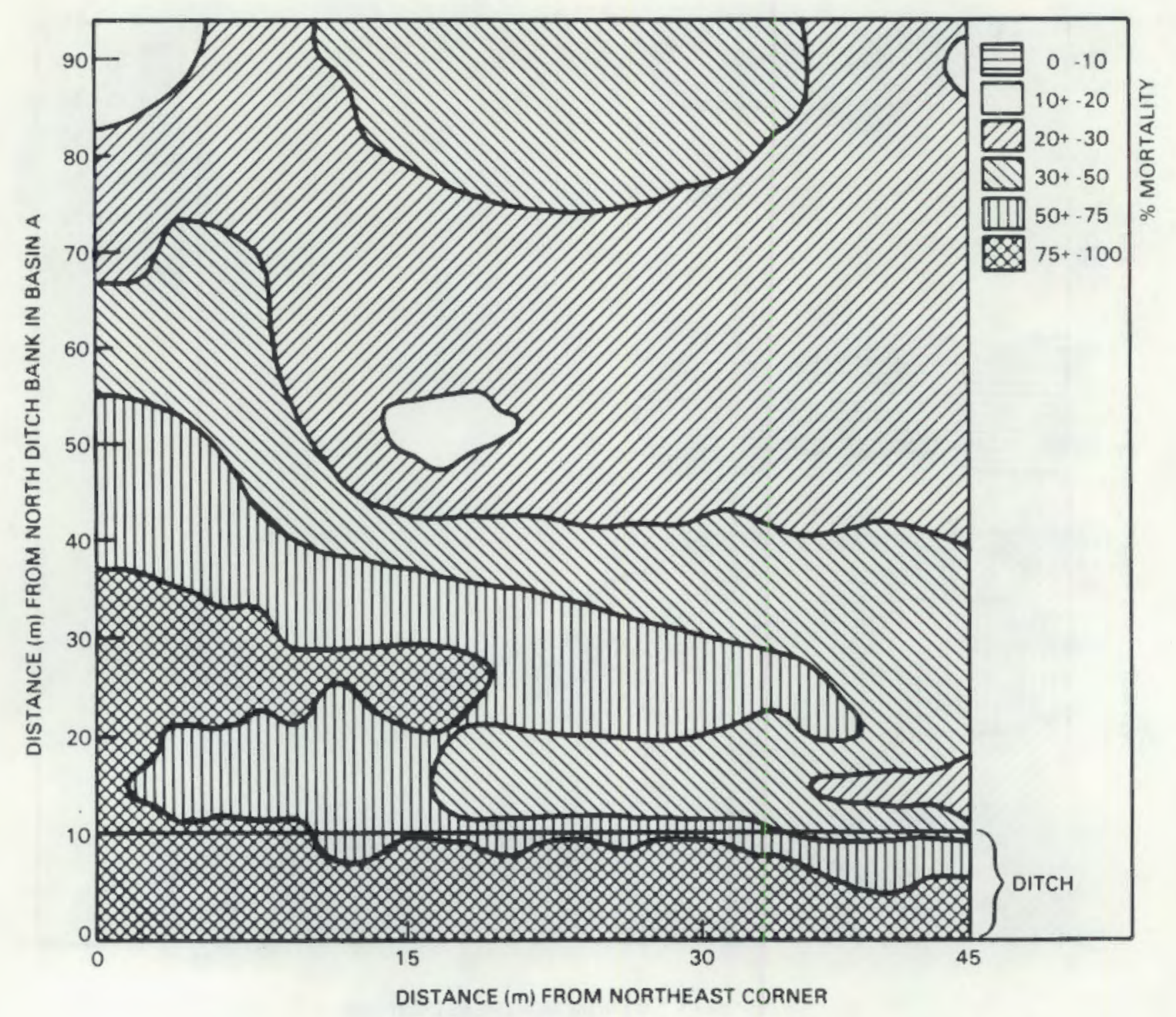

FIGURE 7. Estimated Lettuce Seed Mortality (Based on Kriging) for the 15-30 $\mathrm{cm}$ Soil Fraction from the Rocky Mountain Arsenal

soil fraction would not result in a "clean" site. Cleanup based on the 15-30 cm contour would remove all known contamination, but samples should also have been taken below this depth.

The crosshatching in Figures 8 and 9 shows areas where we estimate that mortality was actually greater than $30 \%$. We constructed these "boxes" by simply drawing a line halfway between grid points with observed mortalities greater than $30 \%$ and those less than $30 \%$. Thus, the crosshatched box at the top of Figure 8 is a consequence of the observed mortality at plot N-9 (42\%) 


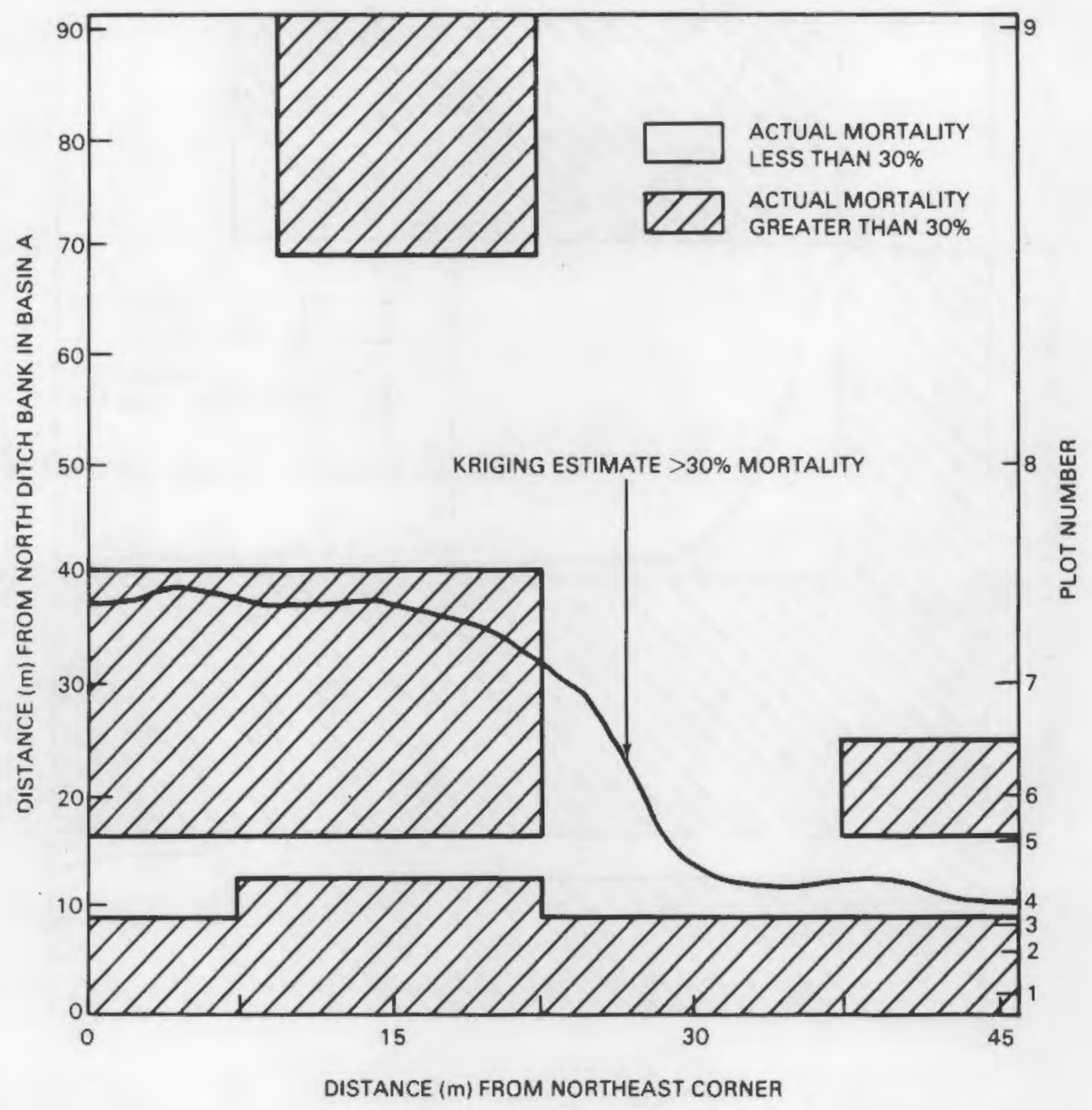

FIGURE 8. A Comparison of Greater than $30 \%$ Lettuce Seed Mortality (Estimated from Kriging) to Observed Lettuce Seed Mortality for the $0-15 \mathrm{~cm}$ Soil Fraction from the Rocky Mountain Arsenal

and the surrounding plots, $\mathrm{P}-9, \mathrm{~N}-8$, and $\mathrm{M}-9$, exhibiting mortalities less than $30 \%$ (Table $8 ; 22,7$ and $14 \%$ respectively). The kriging $>30 \%$ contour apparently does not include this area or high mortality samples at L-6 (100\% observed mortality) because we estimated mortality over small blocks of area. 


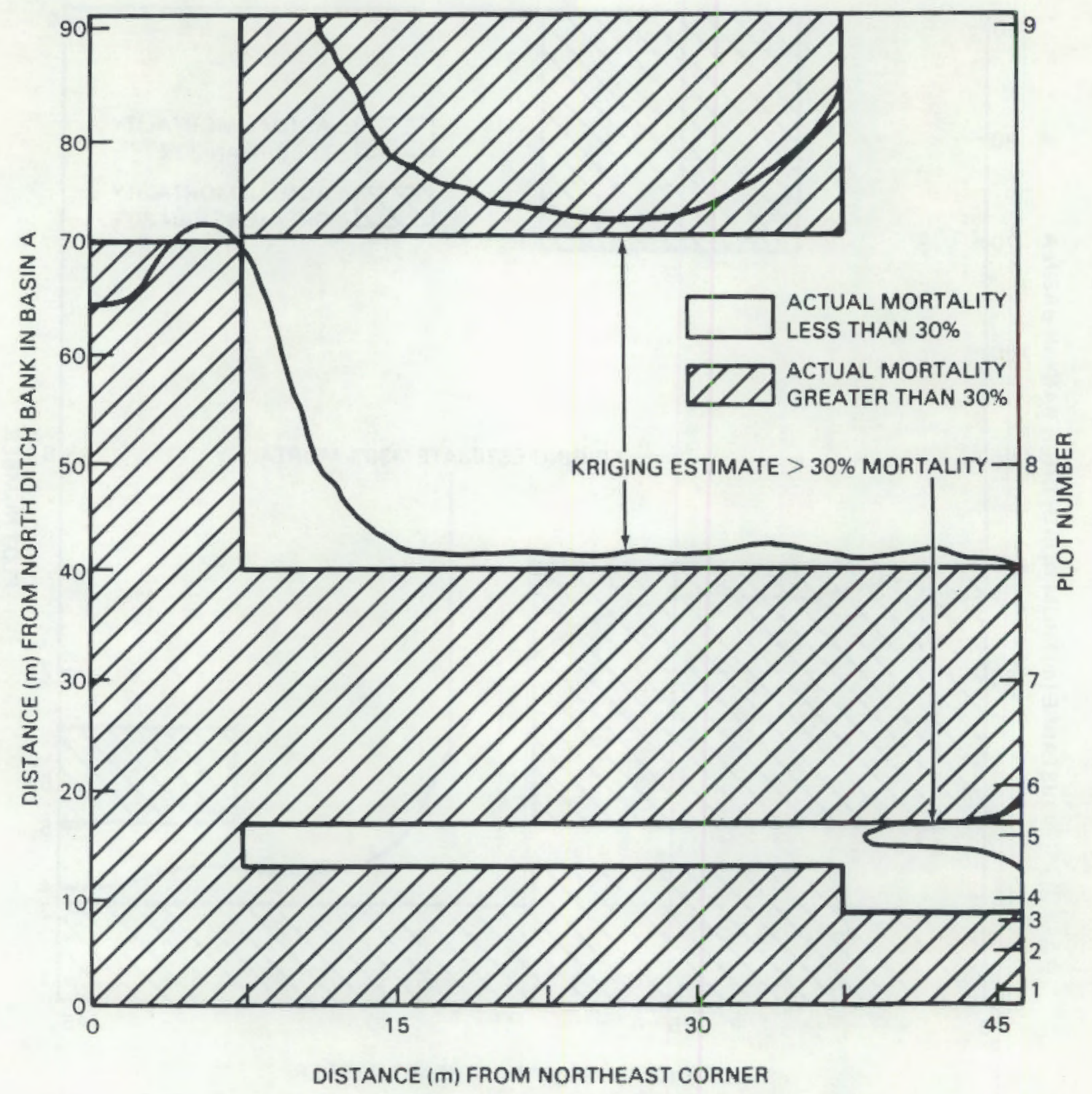

FIGURE 9. A Comparison of Greater than 30\% Lettuce Seed Mortality (Estimated from Kriging) to Observed Lettuce Seed Mortality for the $15-30 \mathrm{~cm}$ Soil Fraction from the Rocky Mountain Arsenal

Had we used punctual or point kriging, the actual observations would be predicted by kriging.

We believe that the use of bioassay of field samples and subsequent kriging analyses offers a practical method to aid in cleanup decisions, 
especialty when accompanied by error estimates for the mortality isopleths. We did not present confidence limits here (limits are dependent on data density, whether block or point kriging is used and the contour of concern; the limits in our study averaged between \pm 10 and $25 \%$ ) because we believe additional demonstrations in diverse environments are needed before we can ascribe general applicability to the entire procedure. 


\section{DISCUSSION AND CONCLUSIONS}

We have conducted a three-phase research program to assess the comparative sensitivity of test organisms to known chemicals, determine the chemical subgroups in field samples using bioassays, and to map the extent of contamination at hazardous chemical waste sites using bioassay results and kriging.

Tests using heavy metals (copper, cadmium and zinc) showed that aigae and Daphnia bioassays were most sensitive, followed, in order of increasing tolerance, by the Microtox, DO rate depletion, root elongation and earthworm (soil contact) bioassays. Good within-organism and element test precision was attained as evidenced by $\mathrm{CV}$ values below 25\%. Root elongation was most sensitive to $94 \% 2,4-D$ acid and a commercial 2,4-D formulation (44.9\% pure). Algae, Microtox and Daphnia exhibited similar 2,4-D tolerances, while earthworms were most resistant. We also found that the $44.9 \% 2,4-D$ formulation was between 7 and 18 times more toxic to algae, Daphnia, and Microtox than the nearly pure 2,4-D acid, which indicates that the inert component of the commercial formulation was also toxic. Onty algae and Daphnia exhibited a toxic response to water soluble forms of the insecticides aldrin, dieldrin and endrin from EPA repository and commercial sources. As with the two herbicide sources, the commercial form of two of the insecticides was more toxic. Thus, testing of herbicides and insecticides intended for fieid use suggests that bioassays may be necessary to assess the bioavailability of components in commercial product fomulations. Results from use of all three chemical subgroups indicate that the algae bioassay may be the most sensitive. Since earthworms appeared to be most resistant to chemicals from the three subgroups, we developed an additional, more sensitive, soil contact phytoassay based on lettuce seed germination.

Our evaluation of soils, soil elutriates and surface and groundwater samples, from the Rocky Mountain Arsenal (RMA) and seven other sites where the major contaminants were known, shows that results from bioassays can aid in ascertaining the presence or absence of some types of contamination. 
Again, algal bioassays were generally most sensitive, but it usually would not be possible to ascertain the toxic components in the absence of other assay results. Bioassays of nine additional RMA samples, where the contaminant history was unknown, showed that the earthworm and lettuce seed soi] contact bioassays were most sensitive, while elutriates stimulated algal growth. The lettuce root elongation test, using $100 \%$ elutriate, also indicated the presence of toxic components, but was less sensitive than the lettuce seed soil contact test. We believe that these results suggest the presence of low levels of water soluble metals and possibly pesticides.

In order to illustrate how bjoassay results could be used to map the toxic potential of a waste site, we conducted a simall-scale field study in a portion of Basin A at the Rocky Mountain Arsena1. We developed seed mortality maps by kriging the resuits from lettuce seed phytoassays of 36 logarithmically spaced soil samples (about $4000 \mathrm{~m}^{2}$ ) at two depths $(0-15 \mathrm{~cm}$ and $15-30 \mathrm{~cm}$ ). Estimated mortality over the sampling area (as well as observed mortality at sample points) was greater at the $15-30 \mathrm{~cm}$ depth. These results indicate that bioassay of soil samples from a statistically designed field study area, accompanied by kriging, can aid in defining the extent of contamination and in site cleanup decisions. Other bioassays conducted using these same samples (when sufficient sample was available) indicate that the modified lettuce seed phytoassay was most sensitive, followed by the earthworm assay. Earthworm mortality was only correlated with lettuce seed mortality when the latter parameter was over 70\%. Thus, the earthworm assay may Tack sensitivity for mapping certain sites. 


\section{REFERENCES}

Bartiett, L., F. W. Rabe, W. H. Funk. 1974. Effects of copper, zinc and cadmium on Selenastrum capricornatum, Water Res. 8(3), 179-185.

Bauer, N. J., R. J. Seidler, M. C. Knittel. 1981. A simple, rapid bioassay for detecting effects of pollutants on bacteria, Bull. Environm. Contam. Toxicol. 27, 577-582.

Beckman Inc. 1982. Microtox System Operating Manual. Beckman Instruments, Inc., Microbics Operations, Carlsbad, California.

Canton, J. H., and 0. M. M. Adema. 1978. Reproducibility of short-term and reproduction toxicity experiments with Oaphnia magna and comparison of the sensitivity of Daphnia magna with Daphnia pulex and Daphnia cucullata in short-term experiments. Hydrobjol. 59, 135.

Chiaudani, G., and M. Vighi. 1978. The use of Selenastrum capricornutum batch cultures in toxicity studies. Mitt. Int. Ver. Limnol. 21, 316-329.

Clark, I. 1982. Practical Geostatistics. Applied Science Publishers, London.

Curtis, C., A. Lima, 5. J. Lozano and G. D. Veith. 1981. An Evaluation of a Bacterial Bioluminescence Bioassay as a Method for Predicting Actual Toxicity of Organic Chemicals to Fish. Publication No. 42, Center for Lake Superior Environmental Studies, University of Wisconsin - Superior, Superior, Wisconsin.

Hoffmann, G. R. 1982. Mutagenicity testing in environmental toxicology. Environ. Scj. Technol. 16:560a-574a.

Johnson, W. W., and M. T. Fintey. 1980. Handbook of Acute Toxicity of Chemicals to Fish and Aquatic Invertebrates. Resource Publication 137, U. S. Department of Interior, Fish and WiIdiife Service.

Journal, A. G., and C. H. H. Huijbregts. 1978, Mining Geostatistics. Academic Press, New York. 
Leischman, A. A., J. C. Greene, and W. E. Miller. 1979. Bibliography of Literature Pertaining to the Genus Selenastrum. EPA 600/9-79-021, U. S. Environmental Protection Agency, Corvallis, Oregon.

Macek, K. J., M. A. Lindberg, S. Sauter, K. S. Buxton, and P. A. Costa. 1976. Toxicity of Four Pesticides to Water Fleas and Fathead Minnows. EPA 600/3-76-099, U. S. Environmental Protection Agency, Duluth, Minnesota.

Mount, D. I., N. A. Thomas, T. J. Norgerg, M. T. Earbour, T. H. Roush, and W. F. Brandes. 1984. Effect of Ambient Toxicity Testing and in Stream Community Response on the Ottawa River, Lima, Ohio. 0WEP8401, U.S. Environmenta 7 Protection Agency, Permits Division, Washington, D.C.

Pearson, E. S., and H. 0. Hartley. 1962. Biometrika Tables for Statisticians, Vol. I. Cambridge University Press, London.

Porcel1a, D. B. 1983. Protocol for Bioassessment of Hazardous Waste Sites. EPA 600/2-83-054, U. S. Environmental Protection Agency, Corvallis, Oregon.

Qureshi Ansar, A., R. N. Coleman and J. H. Paran. 1983. Evaluation and Refinement of the Microtox Test for Use in Toxicity Screening. Proceedings of First International Symposium of Toxicity Testing Using Bacteria, the National Water Research Institute, Canada Center for Inland Waters, Buritington Ontario, Canada.

Randall, W. F., W. H. Dennis and M. C. Waener. 1979. Acute toxicity of dechlorinated DDT, Chlordane, and Lindane to bluegill Lepomis macrochirus and Daphnia magna. Bul1. Environm. Contam. Toxicol. 21, 849.

Ratsch, H. C. 1983. Interlaboratory Root Elongation Testing of Toxic Substances on Selected Plant Species. EPA-600/3-83-051, NTIS \#PB83226126, U. S. Environmental Protection Agency, Corvallis Environmental Research Laboratory, Corvallis, Oregon.

Samoiloff, M. R., J. Bell, D. A. Birkholz, G. R. B. Webster, E. G. Arnott, R. Pulak and F. Madrid. 1983. Combined bioassay-chemical fractionation scheme for the determination and ranking of tcxic chemicals in sediments. Environ. Sci. Technol. 17:329-333. 
Schaeffer, D., H. W. Kerster and K. G. Janardan. 1982. Monitoring toxics by group testing. Environ. Manage. 6:467-469.

Skalski, J. R., and J. M. Thomas. 1984. Improved Field Sampling Design and Compositing Schemes for Cost Effective Detection of Migration and Spills at Commercial Low-Level Radioactive or Chemical Waste Sites. FNL-4935, Pacific Northwest Laboratory, Richland, Washington.

U. S. Environmental Protection Agency. 1980. Ambient Water Quality Criteria for Endrin. EPA 440/5-80-047, Office of Water Regulations and Standards Criteria and Standards Division, Washington, D.C.

U. S. Environmental Protection Agency. 1980. Ambient Water Quality Criteria for Heptachior. EPA 440/5-80-079, Office of Water Regulations and Standards Criteria and Standards Division, Washington, D.C.

U. S. Environmenta1 Protection Agency. 1980. Ambient Water Quality Criteria for Zinc. EPA 440/5-80-079, Offjce of Water Regulations and Standards Criteria and Standards Division, Washington, D.C.

Worthing, C. R., ed. 1979. Pesticide Manual. Sixth edition. British Crop Protection Council. 
. 


\section{DISTRIBUTION}

No. of

Copies

OFFSITE

C. A. Callahan

U.S. Environmental Protection Agency

200 S.W. 35th Street

Corvallis, Oregon 97330

J. C. Greene

U.S. Environmental Protection Agency

200 S.W. 35th Street

Corvallis, Oregon 97330

10 W. E. Miller

U.S. Environmenta? Protection Agency

200 S.W. 35th Street

Corvallis, Oregon 97330

S. A. Peterson

U.S. Environmenta] Protection Agency

200 S.W. 35th Street

Corvallis, Oregon 97330

27 DOE Technical Information Center

Dr. Brian Anderson

Rocky Mountain Arsenal

Commerce City, Colorado 80022

Mr. Bill McNeil

Rocky Mountain Arsenal

Commerce City, Colorado 80022

Dr. Dave Thorne

Rocky Mountain Arsena?

Commerce City, Colorado 80022

Dr. Bill Trautman

Rocky Mountain Arsenal

Commerce City, Colorado 80022
No. of

Copies

OFFSITE

Dr. Michael Witt

Rocky Mountain Arsena 1

Commerce City, Colorado 80022

\section{ONSITE}

22 Pacific Northwest Laboratory

K. E. Byers

J. F. Cline

M. C. McShane

J. C. Simpson

J. R. Skalski

J. M. Thomas (10)

Publishing Coordination (2)

Technical Information (5) 
